$$
\begin{gathered}
\text { UNIVERSIDADE DE BRASíLIA } \\
\text { FACULDADE DE CIÊNCIAS DA SAÚDE } \\
\text { PROGRAMA DE PÓS-GRADUAÇÃO EM SAÚDE COLETIVA }
\end{gathered}
$$

Educação Permanente em Saúde como Estratégia de Gestão: práticas transformadoras na área das DST e aids

Ana Luísa Nepomuceno Silva

$$
\text { Brasília, DF }
$$




\section{ANA LUÍSA NEPOMUCENO SILVA}

Educação Permanente em Saúde como Estratégia de Gestão: práticas transformadoras na área das DST e aids

Dissertação de mestrado profissional apresentada ao Programa de Pós-graduação em Saúde Coletiva da Faculdade de Ciências da Saúde da Universidade de Brasília para obtenção do título de Mestre, inserida na linha de pesquisa Saúde, Cultura e Cidadania.

Orientadora: Profa. Dra. Ana Valéria M. Mendonça

Brasília, DF

2016 


\title{
Educação Permanente em Saúde como Estratégia de Gestão: práticas transformadoras na área das DST e aids
}

\author{
Dissertação de mestrado profissional apresentada \\ ao Programa de Pós-graduação em Saúde \\ Coletiva da Faculdade de Ciências da Saúde da \\ Universidade de Brasília para obtenção do título de \\ Mestre, inserida na linha de pesquisa Saúde, \\ Cultura e Cidadania.
}

Aprovada em 12 de setembro de 2016.

Profa. Dra. Ana Valéria M. Mendonça - UnB

Presidente

Profa. Dra. Ximena Pamela Diaz Bermudez - UnB Examinadora Interna

Profa. Dra. Clélia Maria de Sousa Ferreira Parreira - UnB Examinadora Externa

Profa. Dra. Maria Fátima de Sousa - UnB Examinadora Interna Suplente

Brasília, DF 2016 
AUTORIZO A REPRODUÇÃO TOTAL OU PARCIAL DESTE TRABALHO, POR QUALQUER MEIO CONVENCIONAL OU ELETRÔNICO, PARA FINS DE ESTUDO E PESQUISA, DESDE QUE CITADA A FONTE. 


\section{Agradecimentos}

Sem essas pessoas, este sonho teria sido, apenas, um sonho. À elas, agradeço pelo apoio, amizade, insentivo, confiança e inspiração: Ana Valéria M. Mendonça, Ivo Brito, Mauritância Pereira, Cíntia Clara, Leonardo Almeida, Inocência Negrão, Fábio Mesquita, Adele Benzaken, Elton de Almeida, Natália Oliveira, Priscila Torres e, claro, minha família e amigos. 


\section{Resumo}

Considerando a potencialidade de ações que se contrapõe à rigidez, alienação e controle das estruturas das organizações, este estudo pretende analisar de que forma a educação permanente pode contribuir como possível estratégia para superação desses entraves à gestão no âmbito do Ministério da Saúde. Para isto, relaciona elementos-chave das Políticas Nacionais de Humanização, Educação Permanente em Saúde e Educação Popular em Saúde, compondo diretrizes e princípios essenciais às práticas educativas e de cogestão. Para a realização desse estudo, foi desenvolvida uma análise crítica descritiva, do tipo qualitativo, mediatizado pelo método do estudo de caso. Através da observação participante, foi possível mapear os problemas que justificassem a criação e institucionalização de uma Rede de Educação Permanente no âmbito do Departamento de DST, Aids e Hepatites Virais. Em seguida, foi realizada a coleta de dados, através de pesquisa documental feita a partir dos relatórios dos encontros e sua análise. Verificou-se que, além de qualificar as práticas dos trabalhadores e trabalhadoras deste Departamento que atuam como porta-vozes da Política Nacional de Educação Permanente em Saúde em estados e municípios, a estratégia favoreceu a oportunidade da vivência da educação permanente no cotidiano do serviço, ampliando o debate sobre seu próprio trabalho e estimulando a autonomia e consequente emancipação desses trabalhadores.

Descritores: Educação Permanente em Saúde, Gestão do Trabalho em Saúde, Educação Permanente. 


\begin{abstract}
Considering the potential actions that counteract the rigidity, disposal and control of the organizational structures, this study aims to examine how continuing education can contribute as a possible strategy to overcome the barriers to management under the Ministry of Health. In this order, we relate the key elements of the National Policy of Humanization, Permanent Health Education and Popular Health Education, writing guidelines and principles to educational practice and co-management. To perform this study, we have developed a qualitative descriptive critical analysis, mediated by the case study method. Through participant observation, it was possible to map the problems that justify the creation and institutionalization of a Permanent Education Network under the STD, AIDS and Viral Hepatitis Department. Then the data collection was carried out through the reports of the meetings and the analysis. It was found that, in addition to qualifying the practice of workers of this department to act as the National Policy spokespersons for Continuing Health Education in states and municipalities, the strategy favored the experience ofthe continuing education in the daily service, broadening the debate about their own work, stimulating theautonomy and the consequent emancipation of theworkers.
\end{abstract}

Keywords: Continuing Health Education, Occupational Health Management, Continuing Education 


\section{Lista de siglas e abreviações}

\begin{tabular}{|c|c|}
\hline Aids & Síndrome da Imunodeficiência Adquirida \\
\hline CEAD & Centro de Educação a Distância da Universidade de Brasília \\
\hline CIES & Comissões Integradas de Ensino-Serviço \\
\hline CorpSUS & $\begin{array}{l}\text { Plataforma de interação entre os trabalhadores do Ministério } \\
\text { da Saúde }\end{array}$ \\
\hline DDAHV & Departamento de DST, Aids e Hepatites Virais \\
\hline DST & Doenças Sexualmente Transmissíveis \\
\hline $\mathrm{EaD}$ & Educação a Distância \\
\hline EP & Educação Permanente \\
\hline EPS & Educação Permanente em Saúde \\
\hline HIV & Vírus da Imunodeficiência Humana \\
\hline MS & Ministério da Saúde \\
\hline NE & $\begin{array}{l}\text { Núcleo de Educação do Departamento de DST, Aids e } \\
\text { Hepatites Virais }\end{array}$ \\
\hline PNEPS & Política Nacional de Educação Permanente em Saúde \\
\hline PNEPS-SUS & Política Nacional de Educação Popular em Saúde \\
\hline $\mathrm{PNH}$ & Política Nacional de Humanização \\
\hline PVHA & Pessoas vivendo com HIV/Aids \\
\hline RHS & Recursos Humanos em Saúde \\
\hline RS & Representações Sociais \\
\hline SICLOM & Sistema de Controle Logístico de Medicamentos \\
\hline SISLOGLAB & Sistema Logístico de Insumos Laboratoriais \\
\hline SUS & Sistema Único de Saúde \\
\hline TIC & Tecnologias de Informação e Comunicação \\
\hline
\end{tabular}




\section{Sumário}

$\begin{array}{ll}\text { Apresentação } & 10\end{array}$

1. Introdução 12

1.1. Educação Permanente em Saúde no Departamento de DST, 16 Aids e Hepatites Virais

2. Metodologia 23

2.1.O método do estudo de caso 25

2.2. O método da problematização 26

2.3. Cenário da intervenção 27

2.4.PArticipantes 29

2.5. Processo de monitoramento e avaliação da intervenção 30

2.6. Procedimentos de coleta e análise dos achados 32

2.7. Questões Éticas 33

3. Resultados e Discussão 35

3.1 Categoria: Conceitos 36

3.2 Categoria: Dificuldades 38

$\begin{array}{ll}3.3 \text { Categoria: Potencialidades } & 40\end{array}$

4. Considerações Finais 42

$\begin{array}{ll}\text { Referências } & 45\end{array}$

Apêndices

Apêndice 1: Quadro de resultados por categorias de análise 48

Apêndice 2: Artigo submetido à revista Interface 60

$\begin{array}{ll}\text { Anexo 1: Termo de concordância } & 68\end{array}$

$\begin{array}{ll}\text { Anexo 2: A Rede em imagens } & 69\end{array}$ 


\section{Apresentação}

Esta dissertação pretende apresentar os resultados referentes ao estudo de caso realizado durante o período de fevereiro de 2015 a abril de 2016, fruto do mestrado profissional em saúde coletiva desta Faculdade de Ciências da Saúde.

Como consultora técnica do Departamento de DST, Aids e Hepatites Virais do Ministério da Saúde, vi, nesta modalidade de pós-graduação, a oportunidade para conhecer estratégias que me permitissem introduzir a pesquisa em minha rotina de trabalho e, também, contribuir, no meio acadêmico, com minha experiência profissional.

Antes de adentrarmos na leitura deste estudo, gostaria de contextualizar a escolha do tema e me apresentar não apenas como pesquisadora, mas, principalmente, como sujeito em meu universo particular. Essa explanação talvez justifique ou explique algumas das escolhas aqui feitas e os caminhos que decidi trilhar.

Sou pedagoga de formação e tenho minha experiência profissional voltada a esta área. Especializei-me em Tecnologias de Informação e Comunicação (TIC) em 2004 e, em 2009, em Educação a Distância (EaD). Participei de projetos de pesquisa e extensão na área e, em 2006, assumi, no Centro de Educação a Distância da Universidade de Brasília (CEAD) a gerência da área pedagógica. No Ministério da Saúde, atuo, desde 2008, como consultora em educação mediada por tecnologias. Minha formação, associada às minhas experiências profissionais, permitiram que eu me aperfeiçoasse no planejamento e execução de ações educativas, a distância ou não, e na elaboração de projetos pedagógicos, o que inclui, principalmente, a definição de estratégias metodológicas para que essas ações sejam realizadas.

Por trabalhar, hoje, no Ministério da Saúde e por perceber a falta de conhecimentos mais sistemáticos e fundamentais em relação ao Sistema Único de Saúde, sua estrutura e funcionamento, em minha formação, vi, no Programa de Pós-Graduação em Saúde Coletiva desta Faculdade, a oportunidade para inserir-me verdadeiramente neste campo.

Este estudo traz como temática um pequeno fragmento do meu trabalho no Ministério da Saúde. Como trabalhadora deste Ministério, participei do 
planejamento e da implantação do projeto que será aqui exposto. Como pesquisadora, procurei distanciar-me, numa distância possível, do projeto, para que pudesse analisar seus efeitos.

Espero que os resultados aqui descritos estimulem a reflexão sobre o papel da educação nas práticas e políticas de saúde e sobre suas potencialidades enquanto estratégia para a melhoria da atenção e gestão do trabalho. Apesar da educação não ser considerada um tema novo na área da saúde, ainda se observa grande limitação não apenas no campo conceitual como, principalmente, no campo prático.

O termo educação vem comumente associado a ações restritas e pontuais como capacitações, por exemplo, e seu conceito é facilmente limitado ao que entendemos hoje por educação continuada. Neste estudo, o termo educação se aproxima das políticas em vigor que ampliam este conceito ao que chamamos de educação permanente. Pretendemos, com isto, provocar os profissionais da saúde para a incorporação da educação, em sua rotina profissional, como um meio, não um fim em si mesmo. 


\section{Introdução}

Pensar e desenvolver práticas educativas e humanizadas produtoras de mudança no cotidiano do trabalho é desafiador para atuação no/para o Sistema Único de Saúde (SUS). Diante dos desafios que se apresentam nesse processo, muitas vezes lançamos mão da institucionalização de políticas para nortear e legitimar determinadas práticas. Neste estudo, consideraremos especialmente as Políticas de Humanização, de Educação Popular em Saúde e de Educação Permanente em Saúde por estimularem a criação de ambientes mais participativos e dialógicos e introduzirem princípios e diretrizes fundamentais para o incentivo à autonomia e iniciativas de cogestão nos serviços.

A Política Nacional de Humanização do SUS (PNH) foi criada para responder às dificuldades encontradas em decorrência do baixo investimento no processo formativo dos trabalhadores do SUS no que tange a gestão participativa, ao trabalho em equipe, bem como às práticas de saúde acríticas, que corroboram para o desrespeito aos direitos sanitários (BRASIL, 2004).

Numa tentativa para transformação deste cenário, a $\mathrm{PNH}$ destacou enquanto princípios norteadores:

1. Valorização da dimensão subjetiva e social em todas as práticas de atenção e gestão, fortalecendo/estimulando processos integradores e promotores de compromissos/responsabilização; 2. Estímulo a processos comprometidos com a produção de saúde e com a produção de sujeitos; 3 . Fortalecimento de trabalho em equipe multiprofissional, estimulando a transdisciplinaridade e a grupalidade; 4. Atuação em rede com alta conectividade, de modo cooperativo e solidário, em conformidade com as diretrizes do SUS; 5 . Utilização da informação, da comunicação, da educação permanente e dos espaços da gestão na construção de autonomia e protagonismo de sujeitos e coletivos (BRASIL, 2004, p. 9).

Assim, esta política contesta modelos de atenção e gestão fundados na hierarquização e fragmentação dos processos de trabalho, valoriza a participação dos diversos atores na gestão dos serviços e promove mudanças institucionais partindo, sempre, da análise dos processos de trabalho considerando suas especificidades. Além disso, a PNH sugere maior integração entre as equipes, procurando superar as dissociações entre os que pensam e os que fazem, entre os que planejam e os que executam, entre os que geram e os que cuidam. 
Outra política que merece destaque é a Política Nacional de Educação Popular em Saúde no âmbito do Sistema Único de Saúde (PNEPS-SUS), instituída pela Portaria № 2.761, de 19 de novembro de 2013, que reafirma

[...] o compromisso com a universalidade, a equidade, a integralidade
e a efetiva participação popular no SUS, e propõe uma prática político-
pedagógica que perpassa as ações voltadas para a promoção,
proteção e recuperação da saúde, a partir do diálogo entre a
diversidade de saberes, valorizando os saberes populares, a
ancestralidade, o incentivo à produção individual e coletiva de
conhecimentos e a inserção destes no SUS (BRASIL, 2013, p. 1).

Os princípios orientadores desta política são: diálogo, amorosidade, problematização, construção compartilhada do conhecimento, emancipação e compromisso com a construção do projeto democrático e popular.

Esses princípios podem ser traduzidos a partir de ações e estratégias que provoquem o encontro com o outro de forma respeitosa na perspectiva de favorecer o conhecimento crítico dos envolvidos sobre a realidade, sendo possível promover transformação e humanização; o estímulo ao diálogo sob a perspectiva das trocas emocionais e da sensibilidade de modo a ampliar 0 conhecimento e argumentação organizados apenas pela lógica; relações dialógicas sob a perspectiva de proposição de práticas de saúde provenientes de uma leitura/análise crítica da realidade; processos comunicacionais e pedagógicos entre pessoas e grupos de saberes, culturas e inserções sociais diferentes, na perspectiva de compreender e transformar de modo coletivo as ações de saúde desde suas dimensões teóricas, políticas e práticas, processo eminentemente coletivo e compartilhado de superação e libertação das formas de opressão, exploração, discriminação e violência; o compromisso de construir uma sociedade justa, solidária, democrática, igualitária, soberana e culturalmente diversa mediante lutas sociais e garantia do direito universal à saúde. (BRASIL, 2013, p.1)

Dessa forma, a PNEPS-SUS sugere formas coletivas de aprendizado e investigação, buscando, a partir da participação dos sujeitos e da análise crítica sobre a realidade, um redirecionando a vida social. Com isto, enfatiza não o processo de transmissão de conhecimento, mas a ampliação dos espaços de interação cultural e negociação entre os diversos atores envolvidos em 
determinado problema social, para a construção compartilhada do conhecimento e da organização política necessários à sua superação.

Por sua vez, a Política Nacional de Educação Permanente em Saúde (PNEPS), instituída pela Portaria GM/MS № 1.996, de 2007, proporcionou maior nitidez ao papel de cada uma das três esferas de gestão, bem como estabeleceu os Colegiados de Gestão Regional e os Comissões de Integração EnsinoServiço ${ }^{1}$ (CIES) com suas respectivas funções. Assim, reafirma a importância em levar em consideração as características de cada região e a superação de suas desigualdades, reconhecer onde se deve investir no âmbito das formações e do trabalho, conhecendo a capacidade instalada no que tange as instituições relacionadas às ações de educação na saúde (BRASIL, 2007).

Para Merhy, Feuerwerker \& Ceccim (2006), a Educação Permanente em Saúde (EPS) possibilita a criação de espaços coletivos para debater o trabalho e suas implicações, considerando-o um objeto complexo no qual estão implicadas as relações de poder mais diversas, lógicas corporativas, problemas pouco estruturados e uma baixa governabilidade para o enfrentamento de problemas de grande magnitude e organizações complexas. Esses espaços poderiam, por sua vez, possibilitar que os envolvidos se tornem coautores no processo de reinvenção das instituições de saúde (MERHY, FEUERWERKER \& CECCIM, 2006), remetendo-nos ao compromisso do profissional com a sociedade em sua condição fundamental de agir e refletir (FREIRE, 2002).

Vale ressaltar que a EPS trouxe, para a prática da educação em saúde, uma ampliação conceitual neste campo. Além das ações de capacitação, focadas na prescrição de trabalhos a partir da definição de perfis e competências, a educação tornou-se uma estratégia de gestão capaz de promover reflexão e autonomia aos sujeitos e, se contínua, mudar realidades (CECCIM, 2015).

As reflexões acerca de alternativas para os processos de formação e qualificação de pessoal, bem como os esforços de articulação da educação e trabalho, ganham relevância na área de saúde. Passam a ser valorizados processos de gestão horizontalizados, propiciando um ambiente mais participativo e dialógico não apenas no planejamento como, também, nos

\footnotetext{
1 As CIES são instâncias intersetoriais e interinstitucionais permanentes que participam da formulação, condução e desenvolvimento da Política de Educação Permanente em Saúde.
} 
processos de tomada de decisão. Para isto, torna-se importante que o gestor desenvolva e estimule habilidades de comunicação nos serviços, habilidades estas já apontadas pelas Diretrizes Curriculares Nacionais dos cursos na área da saúde, proporcionando encontros de discussões em que se possam evidenciar situações limites a serem superadas pela equipe. Esses encontros podem ser estimulados a partir do desenvolvimento de ações educativas. Temse, aqui, uma importante aproximação prática entre a comunicação e a educação. Segundo Donato (2003), essa conjunção poderia ser uma das formas pelas quais se torna possível a constituição social de indivíduos capazes de, com novos conhecimentos adquiridos e compartilhados, pensar e transformar a realidade.

Apesar disso, segundo Peduzzi et al (2011), a comunicação ainda é pouco compreendida pelo gestor, sendo vista como mera troca de informações. Tal fato torna-se um desafio e uma mudança de perspectiva em relação ao trabalho em equipe numa visão comunicativa, visando consolidar a prática interprofissional no setor da saúde. Para tanto, faz-se necessário incorporar referenciais problematizadores que podem auxiliar na construção de ambientes dialógicos, críticos e reflexivos, no intuito de utilizar a comunicação como ferramenta no processo de melhoria do trabalho.

Vemos, então, que a EPS, além de sugerir alternativas estruturais aos processos de educação e gestão do trabalho na área da saúde, traz reflexões sobre o que se pretende na área da qualificação profissional e gestão de pessoas.

Para Paim (1994),

Pensar o tema recursos humanos em saúde (RHS) no estágio atual
de desenvolvimento da organização social dos serviços de saúde no
Brasil exige não apenas o refinamento das ferramentas conceituais,
teóricas e metodológicas para a apreensão dessa dimensão da
realidade, mas, sobretudo, a capacidade de análise para identificar,
além de problemas, oportunidades e a criatividade estratégica para
construir saídas políticas numa arena constituída por constelação de
obstáculos. (PAIM, 1994, p.5).

Neste sentido, a EPS pode ser vista como instrumento pedagógico de transformação do trabalho $\mathrm{e}$ do desenvolvimento permanente dos trabalhadores a nível individual e coletivo, na medida em que promove a reflexão das práticas a partir das realidades e contextos específicos onde esses 
trabalhadores estão inseridos. Por isto e por incorporar os princípios norteadores da PNH e PNEPS-SUS, esta política será considerada o eixo norteador deste estudo.

\subsection{Educação Permanente no Departamento de DST, Aids e Hepatites Virais}

O Departamento de DST, Aids e Hepatites Virais (DDAHV) compõe a estrutura da Secretaria de Vigilância em Saúde (SVS) do Ministério da Saúde (MS) de modo que é responsável pela resposta de prevenção, controle e atenção à saúde das pessoas vivendo com HIV/AIDS, outras DST e das Hepatites Virais. É composto por sete coordenações gerais e quatro assessorias, subordinadas a uma Diretoria geral.

A Educação Permanente em Saúde (EPS) compõe o rol de estratégias priorizadas por este Departamento não apenas como política a ser instituída nos estados e municípios, mas, principalmente, como política a ser vivenciada no cotidiano profissional de seus trabalhadores. Este fato tornou-se possível a partir da criação de uma Rede Colaborativa de Educação Permanente, sugerida para tornar as ações educativas do DDAHV coerentes em relação às políticas em destaque e proporcionar ações que problematizem a realidade e permitam a troca de experiências e a construção coletiva de sentidos e práticas.

Esta estratégia baseia-se na perspectiva de promoção de processos educativos e criação de espaços coletivos para reflexão e avaliação sobre os atos produzidos no mundo do trabalho (CECCIM, 2005; MERHY, FEUERWERKER \& CECCIM, 2006).

Pautar a realidade vivida a partir mobilização de sujeitos capazes de "agir e refletir" é fundamental para promover processos de transformação, como afirmou Freire (2002):

[...] como não há homem sem mundo, nem mundo sem homem, não pode haver reflexão e ação fora da relação homem-realidade. Esta relação homem-realidade, homem-mundo, ao contrário do contato animal com o mundo, como já afirmamos, implica a transformação do mundo, cujo produto, por sua vez, condiciona ambas, ação e reflexão (FREIRE, 2002, p.17).

Destaca-se, portanto: 
Se somos atores ativos das cenas de formação e trabalho (produtos e produtores das cenas, em ato), os eventos em cena nos produzem diferença, nos afetam, nos modificam, produzindo abalos em nosso "ser sujeito", colocando-nos em permanente produção. O permanente é o aqui-agora, diante de problemas reais, pessoas reais e equipes reais (CECCIM, 2005, p.167).

Nesse cenário, este estudo adotou a concepção de sujeito apresentada por Freire (2002) em sua característica de ser inacabado, mais ainda por sua capacidade de se reconhecer nessa posição. Na sua trajetória de busca por ser mais por esses sujeitos, a educação ganha destaque, de modo que "o homem deve ser o sujeito de sua própria educação. Não pode ser o objeto dela" (FREIRE, 2002, p.28).

O sujeito que está no mundo deve reconhecer esta condição, bem como compreender que a forma com que está no mundo, condiciona sua consciência desse estar. Estar consciente desta consciência condicionada. Consciência que deve orientar a ação. (FREIRE, 2002).

\begin{abstract}
Somente um ser que é capaz de sair de seu contexto, de "distanciarse" dele para ficar com ele; capaz de admirá-lo para objetivando-o, transformá-lo e, transformando-o, saber-se transformado pela sua própria criação; um ser que é e está sendo no tempo que é o seu, um ser histórico, somente este é capaz, por tudo isto, de comprometer-se (FREIRE, 2002, p.17).
\end{abstract}

A Educação Permanente, neste contexto, torna-se estratégica e potente na medida em que permite que se debata, de forma coletiva, as práticas e concepções vigentes, pactos, acordos, projetos e propostas sob a possibilidade de reorientá-los, reinventar os processos e operar as realidades vivas (MERHY, FEUERWERKER \& CECCIM, 2006). Campos (2000) reforça o que é aqui apresentado no âmbito da EPS quando aborda a problemática da cogestão como alternativa à gestão clássica na área da saúde. Aqui, torna-se estruturante a construção de sentidos para a ação e a garantia das condições para a sua concretização. O poder passa a ser compartilhado a partir da criação de redes e espaços de tomada de decisão coletivas e formulação de projetos. Diminui-se as hierarquias, já que todos passam a atuar conjuntamente para a resolução de problemas.

O Departamento propõe, então, a EPS como conceito pedagógico capaz de promover a agregação entre aprendizado, reflexão crítica sobre o trabalho e 
resolutibilidade da atenção aos portadores de DST e pessoas vivendo com HIV e aids (PVHA), definindo, de forma descentralizada, a ação loco regional desta política e fortalecendo as parcerias interinstitucionais e o controle social sobre a política nacional em DST/HIV/Aids. Além disso, busca desenvolver e implementar ações de educação em saúde em uma perspectiva de reflexão sobre o processo de trabalho e qualificação profissional desses sujeitos, buscando, também, promover encontros e debates sobre as DST e o HIV/Aids. Uma dessas estratégias foi a institucionalização de uma Rede Colaborativa de Educação Permanente, composta por trabalhadores e trabalhadores deste Departamento. Como dizia Freire (1970), educamo-nos sempre em comunhão. Precisamos promover espaços de troca de olhares, percepções, saberes, precisamos promover espaços de diálogo, de construção coletiva. E é, neste cenário, que se torna viável a formação e o fortalecimento de redes de educação.

A simbologia da rede utilizada por Lussi e Marinucci (2007) corrobora com esta premissa e contribuirá para compor o conceito utilizado neste estudo: Para esses autores:

"[...] rede não é apenas a soma de cordas. É uma maneira de entrelaçar as cordas de tal modo que, juntas, conseguem adquirir potencialidades que ultrapassam as capacidades individuais de cada uma delas. Seus nós são necessários para o funcionamento do todo e permitem a um conjunto de cordas de se tornarem uma rede. Se malfeitos, acabam prejudicando o trabalho do todo, se tornando um empecilho, um problema". (LUSSI e MARINUCCI, 2007, p.2).

Assim, o trabalho em rede pode ser visto como uma forma de trabalhar de forma articulada que permite desdobrar as habilidades dos sujeitos envolvidos, garantindo maior eficácia no trabalho e maior eficiência nos resultados. Além disso, assim como os nós de uma rede, a relação entre os sujeitos se faz a partir de vínculos, de união, de uma comunicação entre as partes envolvidas ou mesmo, de problemas comuns.

Apesar de cada ator manter a sua essência ou sua particularidade, há circulação de ideias e propostas que possibilitam forjar uma ação coletiva concreta com vistas ao alcance da direção do bem comum e os sujeitos se abrem para novos conhecimentos (GONÇALVES e GUARÁ, 2010).

Compor uma rede de atores/educadores capazes de promover mudanças institucionais é importante na medida em que, ao trazer os objetos, reflexões e práticas para o debate coletivo na rede, poderá se estabelecer relações e 
processos críticos, que sejam capazes de desdobrar nas equipes "implicando seus agentes, às práticas organizacionais, implicando a instituição e/ou setor da saúde, implicando as políticas nas quais se inscrevem os atos de saúde" (CECCIM, 2005, p.161).

Segundo Lussi e Marinucci (2007) é importante identificar e considerar determinadas características para que seja promovido um efetivo trabalho em rede:

- Apoio: estabelece vínculos sutis entre os envolvidos e pode ser observado na ajuda mútua para a realização de uma tarefa que ambos pretendem ver realizada;

- Parceria: exige que todos os interlocutores participem em todas as instâncias do processo no qual são parceiros, sobretudo nos processos decisórios;

- Rede simétrica: exige de todos os sujeitos uma participação ativa de corresponsabilidade. Mesmo mantendo a autonomia dos sujeitos, a rede estabelece princípios e critérios gerais de ação que, na medida do possível, devem ser respeitados por todos, mesmo em projetos e atividades cuja participação local não seja conjunta;

- Rede assimétrica: exige um centro coordenador ou articulador. O princípio da participação ativa corresponsável dos atores sociais continua, mas gerenciado por um Centro encarregado de coordenar as atividades, sem poder decisório autônomo.

Vale ressaltar que o trabalho em rede, ainda segundo Lussi e Marinucci (2007), pode promover, dentre outras vantagens, um trabalho mais qualificado, mais eficaz, mais abrangente e permanente. Isto porque contribui para um real trabalho coletivo aonde os diversos atores trabalham para atingir objetivos comuns; favorece troca de experiências e perspectivas sobre o conhecimento das realidades, sua interpretação e visão das ações e dos processos a serem ativados; considera a diversidade dos sujeitos; pode estimular a organização dos processos de trabalho; e, por fim, permite maior integração entre as políticas a partir das reflexões promovidas em rede e das necessidades advindas do grupo.

As ideias expostas por Lussi e Marnucci dialogam com aquelas expostas por Capra (1990) quando discorre sobre as teorias acerca dos sistemas e da teia da vida. Para este autor, a interação e a comunicação que ocorre entre os 
diversos atores que compõe uma rede fazem com que as redes produzam um sistema de crenças, explicações e valores tornando-as sustentáveis, já que cada comunicação cria pensamentos e significados que dão origem a novas comunicações, num processo contínuo (CAPRA, 1990).

Uma das estratégias metodológicas que pode favorecer e promover 0 fortalecimento de redes é a roda de conversa, caracterizada como uma metodologia participativa. Segundo Freire (1970), as rodas de conversas possibilitam encontros dialógicos, criando possibilidades de produção e ressignificação de sentido - saberes - sobre as experiências de seus participantes. Além disso, se baseiam na horizontalização das relações de poder, tendo os sujeitos implicados como atores históricos e sociais críticos e reflexivos diante da realidade. Assim, produzem conhecimentos coletivos e contextualizados, ao privilegiarem a fala crítica e a escuta sensível, muitas vezes, de forma lúdica.

Vale ressaltar que as rodas de conversa estão além da simples disposição dos sujeitos em círculo. São, em realidade, uma forma de fazer educação, de considerar os sujeitos, de transformar as realidades. Ou, segundo Campos (2000), uma forma de fazer gestão. O contexto ao qual os sujeitos estão inseridos e as realidades vividas são cruciais, pois é a situação concreta, percebida como limite, que possibilita os atores repensarem o conteúdo oficialmente instituído, bem como, seu processo de formação e trabalho.

Afonso e Abade (2008) destacam que o fundamento metodológico das rodas de conversa é proveniente das oficinas de intervenção psicossocial, tendo como principal objetivo a estruturação de um espaço que permita a reflexão sobre o cotidiano, sua relação com o mundo, com o trabalho e com seu projeto de vida. Por isso, é importante que as rodas sejam desenvolvidas em contexto onde as pessoas possam se expressar, buscando superar seus próprios medos e entraves. Para auxiliá-las nesse processo de quebra dos entraves, bem como para facilitar a comunicação e a interação, se pode fazer uso de técnicas de dinamização de grupo, sendo utilizados recursos lúdicos ou não (FIGUEIRÊDO e QUEIROZ, 2012).

De acordo com Méllo et al. (2007), as rodas de conversa priorizam discussões em torno de uma temática e, no processo dialógico, as pessoas 
podem apresentar suas elaborações, mesmo contraditórias, sendo que cada pessoa instiga a outra a falar, sendo possível se posicionar e ouvir o posicionamento do outro. As rodas de conversa possibilitam a fala e escuta do outro, a vivência e o respeito pelas diferentes opiniões. Como reforçado por Freire (1989), dialogar não é reduzir a opinião do outro e prevalecer sobre ela, não é falar para o outro, mas falar com ele.

Neste processo, ao mesmo tempo em que as pessoas falam suas histórias, buscam compreendê-las por meio do exercício de pensar compartilhado, o qual possibilita a significação dos acontecimentos.

Como método de apoio à gestão, Campos (2000) identifica as rodas como espaços coletivos, caracterizados por estimular a produção de sujeitos e coletivos organizados. Esses espaços são destinados à comunicação (escuta e circulação de informações sobre desejos, interesses e aspectos da realidade), à elaboração (análise da escuta e das informações) e tomada de decisão (prioridades, projetos e contratos).

Este estudo de caso teve como objetivo geral analisar a experiência vivenciada no Departamento de DST, Aids e Hepatites Virais (DDAHV) para a institucionalização da Rede Colaborativa de Educação Permanente, realizada a partir de rodas de conversa e ainda, como objetivos específicos, oportunizar o diálogo entre os profissionais da DDAHV para a melhoria de sua atuação no planejamento e execução de ações pedagógicas e educativas nos cenários de atuação e identificar os conceitos, dificuldades e potencialidades quanto à incorporação de práticas de educação permanente em saúde em seu cotidiano de trabalho.

Apesar de não estarem inseridas no planejamento estratégico do Departamento, as oito oficinas realizadas e que foram ponto de estudo e análise desta investigação, envolveram questões subjetivas e anteriores.

Esta ação se justifica pela identificação de problemas comunicacionais entre seus trabalhadores e pela constatação de incongruências e inadequações nas práticas educativas planejadas e realizadas pelos trabalhadores e trabalhadoras deste Departamento no que tange a atual Política Nacional de Educação Permanente em Saúde. Estas práticas foram desenvolvidas no âmbito do DDAHV. 
Muitas ações educativas ainda são vistas, por esses trabalhadores, como processos isolados, se restringindo a meras capacitações indicadas como respostas para quase todos os problemas. Além disso, observa-se, como estratégias pedagógicas para a realização dessas ações, metodologias tradicionais, nas quais pouco se constrói coletivamente, ações pouco contextualizadas às realidades locais e ações educativas desarticuladas da gestão e dos processos de trabalho.

Os elementos trazidos que justificam este estudo, foram levantados a partir da observação participante da pesquisadora durante a execução das oficinas relacionadas à Roda de Conversa, da análise documental realizada a partir dos relatórios de cada um desses encontros e, anterior a isto, de sua experiência como trabalhadora do Núcleo de Educação (NE) Departamento de DST, Aids e Hepatites Virais, cenário desta pesquisa. Cabe, a este núcleo, articular e apoiar a implementação e acompanhamento de processos educativos desenvolvidos em conjunto com as demais áreas deste DDAHV. 


\section{Metodologia}

Segundo Minayo (2008), pode-se compreender como Pesquisa Social, os diversos tipos de investigação, que tratam do ser humano em sociedade, de suas relações e instituições de sua história e de sua produção simbólica. Isto possibilita dizer que, nesse tipo de pesquisa, são evidenciados os aspectos individuais, as opiniões, as atitudes, as motivações, os comportamentos, dentre outros. Seu objeto é, essencialmente, qualitativo, pois a realidade social é o próprio dinamismo da vida individual e coletiva, com toda riqueza dos significados. Essa realidade é mais valiosa do que qualquer teoria, do que qualquer política ou teórico que tente explicá-la (MINAYO, 2008).

Neste tipo de pesquisa busca-se, nas ações e relações humanas, o significado que não é possível ser captado pela quantificação. Como assume uma realidade dinâmica e faz uso da observação naturalista, o método qualitativo não controla os procedimentos utilizados e não elabora previamente suas hipóteses. A investigação ocorre em ambiente natural, envolvendo-se nas situações reais do cotidiano, sempre em busca do significado da ação social segundo a ótica dos sujeitos pesquisados (SILVERMAN, 1997). Os sujeitos que compõe o corpus da pesquisa são vistos dentro de seus ambientes naturais, nas suas relações interpessoais, em ambientes e relações nos quais constroem e reconstroem a realidade.

A pesquisa qualitativa é, então, uma atividade que se impõe no decorrer do contexto situacional, tendo, na localização e implicação do pesquisador em relação ao objeto de estudo e seu contexto, um compromisso com a mudança. (DENZIN, LINCOLN, 2006). E é, neste sentido, que se relaciona com o pensamento de Paulo Freire, pois ambos se preocupam com o desenvolvimento da realidade social, desvelando o que está oculto, permitindo assim, que os participantes encontrem novos caminhos diante da realidade concreta (HEIDEMANN, 2006). Além disso, pode conduzir à tomada de decisões, através da discussão e do debate, revelando mais do que atitudes e comportamento dos indivíduos, preocupando-se, pois, em entender os motivos, os discursos e as origens das ações (VICTORIA; KNAUTH; HASSEN, 2000).

As análises qualitativas podem ser caracterizadas por serem essencialmente descritivas fundamentadas pelo modo de ser do homem e pela 
sua cosmovisão social (MARTINS e BICUDO, 1989). A pesquisa qualitativa pode descrever detalhadamente os procedimentos de campo, dando à mesma, um grau de objetivação do fenômeno estudado (MORGAN, 1983). Além disso, as descrições podem ser ricas e bem fundamentadas, levando a pesquisa a oferecer um maior grau de reflexibilidade ao pesquisador (VIEIRA ZOUAIN, 2004).

Pesquisas de natureza qualitativa envolvem uma grande variedade de materiais empíricos, que podem ser estudos de caso, relatos de experiência, histórias de vida, interações e outros materiais que descrevam a rotina e os significados da vida humana em grupos.

Para a realização desse estudo, foi desenvolvida uma análise crítica descritiva, do tipo qualitativo, mediatizado pelo método do estudo de caso. Através desse procedimento, realizou-se observação participante para 0 mapeamento de problemas que justificassem a criação e institucionalização da Rede Colaborativa de Educação Permanente.

Por intermédio da análise documental dos relatórios elaborados foi desenvolvida a identificação da evolução conceitual dos termos e revelou-se de que maneira a educação é considerada hoje nas práticas dessas áreas que compunham a rede. Esta fonte de análise é considerada essencial neste tipo de investigação, que se propõe a observar o processo de amadurecimento dos sujeitos participantes das atividades de observação, seus conhecimentos associados aos demais, e compartilhados com estes, bem como exemplos de práticas e outras vivências. (CELLARD, 2008).

Godoy (1995) define a pesquisa documental como a análise de documentos de diversas naturezas, buscando interpretações novas e/ou complementares. Assim, a análise dos encontros realizados com os participantes se deu por meio da criação de categorias, classificações dos elementos encontrados de acordo com as características comuns. Este processo pode ser adotado para a análise de qualquer pesquisa qualitativa, permite-nos trabalhar um conceito que abrange as várias expressões e ideias mencionadas (GOMES, 2001).

Para Minayo e Sanches (1993), o material de análise está na fala, nas expressões cotidianas e nas afetividades presentes nos discursos. As categorias de análise, portanto foram em número de quatro. Elas não foram pré- 
estabelecidas, emergiram do processo de classificação e a leitura crítica do material dos encontros realizados foi sistematizada por temas. (Apêndice 1).

As categorias trabalhadas foram os Conceitos, as Dificuldades, Potencialidades e Encaminhamentos, descritas como:

I. Conceitos: Os conceitos sobre educação (ou similar) vieram do grupo, como estes conceitos sobre educação (ou similar) foram construídos coletivamente e como a educação foi discutida nos encontros realizados. Teve como subcategorias os conceitos de Educação, Educação Permanente e Educação Continuada.

II. Dificuldades: Relato das dificuldades e desafios mencionados pelo coletivo nos encontros. As dificuldades relacionadas ao trabalho ou encontradas para a realização de determinadas ações.

III. Potencialidades: Relato das potências relacionadas ao trabalho ou a realização de determinadas ações.

IV. Encaminhamentos: Sugestões e Propostas do coletivo em relação ao trabalho e a educação, apresentados nas Considerações Finais deste estudo.

\subsection{0 método do estudo de caso}

O estudo de caso é um tipo de pesquisa qualitativa e é frequentemente utilizado para coleta de dados na área de estudos organizacionais. Ele deve ser aplicado quando o pesquisador tiver interesse em pesquisar uma situação singular, particular. O caso deve ser bem delimitado devendo ter seus contornos claramente definidos no desenvolver do estudo.

Segundo Ventura (2007), toda pesquisa científica deve delimitar seu objeto de estudo e o universo que será estudado. Para ela, o estudo de caso se contrapõe aos estudos agregados por ter, como intensão, estudar uma unidade ou parte de um todo. O caso deve ser específico, bem delimitado, contextualizado em tempo e lugar para que se possa realizar uma busca circunstanciada de informações. Apesar disso, é fundamental não restringir o estudo apenas àquele caso, mas, sim, considerar o que este caso sugere a respeito de um contexto mais abrangente. 
Ainda segundo Ventura (2007), os estudos de caso podem ser classificados em:

“(...) intrínseco, quando procura compreender melhor um caso em particular em si; instrumental, quando se examina um caso para se compreender melhor outra questão, algo mais amplo, orientar estudos ou ser instrumento de para pesquisas posteriores, e coletivo, quando estende o estudo a outros casos instrumentais conexos com o objetivo de ampliar a compreensão ou a teorização sobre um conjunto ainda maior de casos" (VENTURA, 2007, p. 384).

No caso de estudos que priorizam a abordagem qualitativa da pesquisa, como estudos de caso naturalísticos, Ventura (2007) destaca, ainda, características que podem ser consideradas fundamentais: interpretação dos dados feita no contexto busca constante de novas respostas e indagações, retratação profunda e completa da realidade, o uso de uma variedade de fontes de informação, a possibilidade de generalizações naturalísticas e a revelação dos diferentes pontos de vista sobre o objeto de estudo. (VENTURA, 2007, p. 394).

Apesar de não ser possível definir um roteiro rígido para a delimitação dos estudos de caso, sobretudo os naturalísticos, Ventura (2007) estabelece fases para a sua realização, a saber: exploratória (definição dos pontos críticos, estabelecimento de contatos iniciais para a entrada em campo e localização das fontes de dados necessárias ao estudo); delimitação do estudo (definição dos focos da investigação e estabelecimento de contornos do estudo para proceder a coleta de informações); análise sistemática e elaboração do relatório. Este estudo procurou seguir as etapas acima descritas para a sua realização.

\subsection{0 método da problematização}

O método da problematização leva em consideração o significado de um determinado assunto e tem, por finalidade, situa-lo, no intuito de compreender o que se sabe sobre ele. Isso pode ser evidenciado por diversas maneiras, como por exemplo, considerar o conhecimento prévio de uma pessoa, e pode embasar a justificativa de uma pesquisa ou um projeto (BUENO, 2009; FREIRE, 2011).

Paulo Freire descreve a problematização, como um sentido de inserção crítica da realidade, para dela, retirar os elementos que evidenciarão o significado e direção às aprendizagens. $\mathrm{Na}$ ação-reflexão-ação, é possível 
construir os conhecimentos, considerando no contexto, as implicações pessoais, assim como, as interações entre os diferentes sujeitos que aprendem e ensinam (FREIRE, 2011).

Este referencial freireano é considerado um método aberto, ativo, emancipatório, dialogal, crítico e reflexivo, que promove uma relação horizontal entre pesquisador/pesquisandos e/ou educador/educandos, os quais, compreendem e possivelmente, modifiquem a realidade que estão inseridos. Há que se enfatizar a postura transformadora, ao se conscientizarem do movimento que ocorre, no seu entorno (BUENO, 2009). Nessa postura problematizadora, há possibilidade de se trabalhar uma prática comprometida com a educação, associada à liberdade do ser, no intuito de incentivar a tomada de consciência dos sujeitos, para oportunizar mudanças e transformações (FREIRE, 1992; BUENO, 1997).

Para a realização desse estudo procurou-se, a partir desse método, provocar debates entre os participantes da Rede Colaborativa de Educação Permanente durante as oito rodas de conversa observadas trazendo sempre como referências suas realidades e seu cotidiano de trabalho. Desta forma foi possível descrever, nos relatórios, uma construção individual e coletiva não apenas de conceitos, mas de narrativas e valores sobre educação e atuação profissional. A problematização tornou-se aqui, uma postura, uma forma de discutir possíveis verdades e repensar atuais práticas.

\subsection{Cenário da intervenção}

A intervenção em destaque (Rede Colaborativa de Educação Permanente), objeto desta pesquisa, foi desenhada para ser realizada no Departamento de DST, Aids e Hepatites Virais do Ministério da Saúde a partir de fevereiro de 2015, momento este de elaboração do projeto. Apesar de ser considerado um processo contínuo sem data prevista de término, para fins deste estudo, definiu-se como limite de análise dos dados a data de abril de 2016. Espera-se que esta intervenção possa ser ampliada para as demais áreas e secretarias do Ministério da Saúde, considerando ser este um processo importante para a qualificação das ações educativas e de gestão desenvolvidas por este órgão. 
Para a institucionalização da Rede Colaborativa de Educação Permanente no Departamento de DST, Aids e hepatites Virais do Ministério da Saúde, foram respeitadas etapas formais para aprovação e operacionalização da ação. São elas:

> Pactuação com a Diretoria e coordenadores de áreas:

- Apresentação da proposta de intervenção para a Diretoria do DDAHV;

- Apresentação da proposta para as assessorias e coordenações do Departamento, após a aprovação da Diretoria;

Levantamento de atores para composição da Rede Colaborativa de Educação Permanente do DDAHV:

- Contato com os coordenadores e gerentes das áreas e identificação de atores de acordo com as afinidades e competências identificadas, que atuassem nas atividades do Departamento junto aos Estados da Federação e/ou que desejassem participar da rede em construção;

Realização de oficinas quinzenais com a rede estabelecida:

- Debate sobre conceito(s) de educação com a rede tendo como fundamento os referenciais supracitados, dentre outros que corroboram com a perspectiva emancipadora;

- Definição dos objetos, reflexões e práticas educativas relacionadas ao cotidiano do trabalho de modo a favorecer a/o:

- Identificação de como cada área tem realizado seus processos educativos e quais são os nós enfrentados nesses processos, estabelecendo conjuntamente estratégias de superação;

- Identificação das potências relacionadas a cada objeto, reflexão e prática, aquelas relacionadas à conjuntura do Departamento, as que envolvem a relação com atores externos ou o que o grupo identificar;

- Discussão e definição do papel dos atores que compõem a rede, bem como sua importância no que tange a ativação dos debates sobre educação nas áreas técnicas embasados pelas políticas; 
- Desenvolvimento de uma oficina para desenho do modelo lógico da intervenção junto com os participantes da rede de modo a implicar cada um no processo do monitoramento e avaliação;

- Elaboração de fluxos para o planejamento, desenvolvimento e acompanhamento das ações educativas no DDAHV.

- Identificação de atores para atuarem como referência em educação em cada área técnica do DDAHV no intuito de compor a Rede Colaborativa de Educação Permanente;

- Realização de encontros dialógicos entre trabalhadores e trabalhadoras do DDAHV sobre as políticas, pautas e objetos de educação permanente promovendo a reflexão crítica e propositiva no que tange as ações e estratégias educacionais que têm sido desenvolvidas pelas áreas técnicas do DDAHV;

- Identificação e discussão sobre os nós críticos que as áreas técnicas enfrentam no âmbito do planejamento, realização e avaliação das ações educativas a fim de formular mecanismos coletivos para superá-los;

- Reorganização dos fluxos internos relacionados às ações de educação;

- Criação de mecanismos para sistematização dos processos e práticas educativas desenvolvidas no DDAHV.

\subsection{Participantes}

A intervenção analisada foi desenvolvida para trabalhadores e trabalhadoras do Departamento de DST, Aids e Hepatites Virais do Ministério da Saúde.

Para composição da Rede Colaborativa em Educação Permanente, pensou-se na escolha de pelo menos um técnico de cada coordenação e assessoria do DDAHV. As coordenações gerais dividem-se em Prevenção e Articulação Social; Laboratório; Assistência e Tratamento; Informações Estratégicas; Logística; Gestão e Governança; e Hepatites Virais. Enquanto as assessorias distribuem-se nos eixos de Comunicação; Ações Estratégicas; Jurídico e de Monitoramento e Avaliação. 
Nessa perspectiva, formulou-se um perfil de afinidades e competências para identificação dos mesmos em suas respectivas áreas:

- Interesse, afinidade e disposição para atuar com o planejamento, implementação e monitoramento de processos educativos desenvolvidos no Departamento;

- Aproximação com áreas educativas com ações educativas em sua área de atuação;

- Aptidão para estabelecer a interlocução entre os técnicos do DDAHV, no que se refere à proposição de processos educativos integrados, focados em metodologias participativas de ensino-aprendizagem;

- Habilidade para articular parcerias (segmentos da gestão, serviço, universidade e sociedade civil) que subsidiem a criação e o desenvolvimento de ações educativas sob a ótica da Política Nacional de Educação Permanente em Saúde, Política Nacional de Educação Popular em Saúde e Política Nacional de Humanização.

O envolvimento com alguma ação estratégica para o DDAHV poderia ser mais um fator que influenciaria a composição dessa rede, mesmo que de forma temporária. Um exemplo importante é o das atividades que estão sendo desenvolvidas nos estados cuja taxa de detecção do HIV é maior que a média nacional, como Amazonas, Rio de Janeiro, Rio Grande do Sul e Santa Catarina.

Assim, a identificação de atores foi um passo importante para o desenvolvimento da estratégia, que, como já apresentado anteriormente, tem o mundo do trabalho como objeto central (a partir da reflexão sobre as ações educativas), com a potencialidade da atuação em sua micropolítica e do incentivo de encontro entre sujeitos capazes de promover reflexões e transformações na sua ação produtiva a partir de atos coletivos (MERHY, FEUERWERKER \& CECCIM, 2006).

\subsection{Processo de monitoramento e avaliação da intervenção}

Entende-se aqui como monitoramento e avaliação da intervenção a forma que os membros da Rede Colaborativa de Educação Permanente 
acompanharão e refletirão sobre o processo de planejamento e realização desse processo.

Tendo em vista que a intervenção apresentada age na dimensão do desenvolvimento de diretrizes e práticas no âmbito da Educação Permanente, é importante delinear uma estratégia de avaliação que seja coerente com esta perspectiva. Para Champagne et al (2011a) avaliar significa:

\begin{abstract}
[...] emitir um juízo de valor sobre uma intervenção, implementando um dispositivo capaz de fornecer informações cientificamente válidas e socialmente legítimas sobre essa intervenção ou sobre qualquer um de seus componentes, com o objetivo de proceder de modo a que os diferentes atores envolvidos, cujos campos de julgamento são por vezes diferentes, estejam aptos a se posicionar sobre a intervenção para que possam construir individual ou coletivamente um julgamento que possa se traduzir em ações. (CHAMPAGNE et al. 2011a, p.44).
\end{abstract}

O processo de monitoramento e avaliação da estratégia foi desenvolvido ao longo dos encontros junto com os atores que a compõe, tendo em vista que atuarão, a partir de um processo emancipatório, na dimensão da transformação das práticas educativas desenvolvidas no Departamento. Destacam-se como elementos deste monitoramento e avaliação:

- Desenvolvimento, ao longo dos encontros, de uma síntese ou conjunto de diretrizes e princípios que possam nortear as ações educativas, promovendo aproximação em relação à Política Nacional de Educação Permanente, Política Nacional de Educação Popular em Saúde e Política Nacional de Humanização;

- Sistematização e publicização dos encontros;

- Sistematização de cada encontro de modo a construir uma memória do processo que foi desenvolvido;

- Envio das sistematizações para todos os participantes, coordenadores, gerentes e Diretoria;

- Elaboração de uma publicação conjunta com as experiências vividas no processo de desenvolvimento da rede;

- Elaboração de uma página virtual para debates, trocas de materiais, bem como desenvolvimento de projetos em conjunto a partir do CorpSUS. 
Para desenhar a estratégia de avaliação foram esboçados dois encontros com carga horária total correspondente a 8 horas, da seguinte forma:

(1) Primeiro Encontro - 4h/a

- Primeiro Momento: debater os principais objetivos da rede e os papeis de cada ator na mesma; discutir os princípios e diretrizes estruturantes das políticas em destaque;

- Segundo Momento: abordar a importância de planejar, monitorar e avaliar as práticas desenvolvidas, a partir da discussão dos aspectos conceituais e práticas; com base na discussão dos objetivos, esboçar marcos intermediários/produtos, ações e resultados prioritários;

(2) Segundo Encontro - 4h/a

- Primeiro Momento: construção em grupo do modelo lógico da estratégia, bem como elaboração de uma agenda para realização do monitoramento;

- Segundo Momento: debate e escolha da melhor estratégia de avaliação da intervenção.

Destaca-se que a escolha do processo de modelização justifica-se pelo fato de permitir a explicitação da relação entre a intervenção com seus efeitos na medida em que promove a "conceitualização dos vínculos entre as estruturas, os processos e os resultados" (CHAMPAGNE et al, p.63, 2011b). Além disso, corrobora para o processo de avaliação, tendo em vista que pode evidenciar se há diferenças do que foi previsto para a intervenção em relação ao que foi implantado, esclarecer os objetivos da intervenção, dentre outras possibilidades de acordo com o tipo de avaliação (CHAMPAGNE et al, 2011b). Cada encontro foi sistematizado de modo a gerar uma memória de todo o processo, bem como divulgar para os participantes da rede, a coordenações, gerências e Diretoria.

Infelizmente seu período de realização não coincidiu com o de execução deste estudo de caso, que, certamente, usufruiria de seus resultados para uma análise significativa do processo.

\subsection{Procedimentos de coleta e de análise dos achados}


Como já destacado anteriormente, a pesquisa qualitativa permite que os resultados das análises sejam feitos de maneira subjetiva respeitando, claro, o rigor exigido para que seus resultados tenham significância científica. Este estudo utilizou como técnica para coleta de dados, essencialmente, a observação participante e a sistematização de cada oficina realizada.

Durante a execução da intervenção, foi utilizado o método da problematização para a promoção dos debates e interações entre os participantes. A partir daí foram elaborados relatórios detalhados para o registro de dados do local do estudo assim como dos trabalhadores que compunham a Rede Colaborativa de Educação Permanente.

Cada relatório era composto do plano previsto para ser trabalhado no dia do encontro/roda de conversa, especificidades sobre os materiais utilizados para a realização das atividades, síntese das discussões entre os participantes e síntese das apresentações e interações feitas com os facilitadores, resultado da avaliação de reação preenchida pelos participantes e relação de encaminhamentos.

Além disso, os relatórios continham, quando explicitados, os encaminhamentos ou possíveis desdobramentos para os encontros seguintes. A partir desses documentos, foi possível elaborar categorias de análise que permitissem a compreensão e a interpretação do conteúdo discursivo desses atores, a partir da utilização do método da Análise de Conteúdo.

Para este estudo foram definidas como categorias de análise: conceituação de educação e suas variantes, dificuldades relatadas sobre práticas educativas no trabalho e potencialidades relatadas sobre práticas educativas no trabalho, além dos encaminhamentos propostos pelo grupo. Essas categorias representam a intencionalidade do estudo, que pretende analisar de que a forma a experiência vivenciada no Departamento de DST, Aids e Hepatites Virais (DDAHV) para a criação e manutenção da Rede Colaborativa de Educação Permanente contribui para a melhoria das ações educativas desenvolvidas por profissionais que atuam neste Departamento e para a melhoria da interação e comunicação entre esses trabalhadores.

\subsection{Questões Éticas}


Por se tratar de um estudo a partir de base secundária, os relatórios oriundos das oito rodas de conversa realizadas pela Rede Colaborativa de Educação Permanente do Departamento de DST, Aids e Hepatites Virais do Ministério da Saúde, foram oficialmente cedidos pela Diretora deste Departamento, Dra. Adele Benzaken, para fins desta pesquisa (Anexo 1). Deste modo, dispensa-se a aprovação pelo Comitê de Ética em Pesquisa da Faculdade de Ciências da Saúde da Universidade de Brasília (CEP-FS/UnB).

Quanto à abordagem direta aos relatórios e suas primeiras interpretações, foi possível a partir da inserção da pesquisadora nas atividades das oficinas como sujeito ativo. Destaca-se ainda que a pesquisa desenvolvida junto ao coletivo de profissionais da DDAHV teve momentos de observação participante, os quais possibilitaram a interação com os membros da Rede, de modo a garantir a lisura das interpretações em seus conjuntos ético, social e institucional. 


\section{Resultados e Discussão}

Uma vez instituída a Rede Colaborativa de Educação Permanente, foram realizados, de fevereiro de 2015 a abril de 2016, oito encontros com os trabalhadores e trabalhadoras que a compõe (Anexo 2). Cada um dos encontros, desenvolvidos a partir da metodologia de rodas de conversa, contou com a participação de um ou mais representantes de cada uma das áreas do Departamento de DST, Aids e Hepatites Virais, totalizando a média de 15 participantes por encontro. Além dos técnicos do Núcleo de Educação, estavam presentes representantes da Assessoria de Ações Estratégias, da Assessoria de Comunicação, Assessoria de Monitoramento e Avaliação, Assessoria de Cooperação Internacional, Coordenação de Informações Estratégicas, Coordenação Geral de Hepatites Virais, Coordenação Geral de Assistência e Tratamento em DST e Aids, Coordenação Geral de Laboratórios, Coordenação Geral de Prevenção e Articulação Social e Coordenação de Geral de Logística.

Os temas das rodas de conversa versaram sobre educação e trabalho, procurando atingir o objetivo inicialmente proposto para a intervenção: oportunizar o diálogo entre esses profissionais para a melhoria de sua atuação em ações pedagógicas e educativas nas atividades do Departamento junto aos Estados brasileiros e identificar a possibilidade de incorporação de práticas de educação permanente em saúde em seu cotidiano de trabalho.

Como já mencionado, a metodologia utilizada pela pesquisadora nas rodas de conversa foi a problematização, considerando a intencionalidade de se repensar a realidade e não, simplesmente, reproduzi-la. Cada encontro gerou um relatório descritivo que permitiu a análise, a compreensão e a interpretação dos conteúdos discursivos, posteriormente analisados a partir da análise de conteúdo.

Os discursos analisados a partir do conjunto dos textos gerados com a síntese dos relatórios de cada uma das oficinas, bem como suas discussões e releituras junto aos profissionais e colaboradores do DDAHV, possibilitaram a identificação de três categorias aqui destacadas (conceitos, dificuldades e potencialidades) e uma quarta, de encaminhamentos, aqui suprimida, mas utilizada para as considerações finais do estudo. Assim, discorreremos a seguir sobre cada uma das categorias. 


\subsection{Categoria: Conceitos}

Nesta categoria, pretendeu-se compreender os conceitos sobre educação trazidos pelo grupo e sua evolução a partir dos encontros realizados. A pergunta chave elaborada para esta análise foi: Que conceitos sobre educação (ou similar) vieram do grupo? Que conceitos sobre educação (ou similar) foram construídos coletivamente? Como a educação aparece nos discursos?

Sobre esta abordagem, os textos analisados apontaram que o que vem à mente dos participantes das atividades quando se pensa em educação é: construção, conhecimento, a emancipação, que se dá no processo educativo, ato político em conjunto com a aprendizagem compartilhada, com vistas à reflexão para a transformação de realidades e emancipação de sujeitos, respeito e atitude. Para eles, a educação é uma ferramenta transversal, que favorece a mudança de prática e induz a aceitabilidade. Alguns participantes relataram que há ainda a possibilidade de não haver um conceito fechado, mas sim dinâmico sobre educação.

Quanto aos processos educativos, os participantes consideraram que devem ser flexíveis a ponto de serem repensados a partir da dinâmica junto ao grupo e repactuados junto com o mesmo. Por ter um componente relacional, os processos educativos estão submetidos à ação do diálogo, tensionamentos e fatores que podem emergir de acontecimentos vivenciados dentro do grupo ou fora dele o que requer um intenso processo de reflexão conjunta para superar eventuais obstáculos.

Para os participantes, a Educação Continuada pode ser entendida como uma ação pontual, que encerra em si um desenho que inclui início, meio e fim com um enfoque para trabalhar conteúdos específicos, com grupos específicos, independente da metodologia utilizada. É pensada geralmente para desenvolver algum tipo de competência e/ou saber, que pode ou não responder uma necessidade do serviço. O processo pode se encerrar em algum momento e não mais acontecer. Pontualmente, é possível aprender e aprimorar uma técnica. Algumas falas ponderaram que, a depender da metodologia utilizada nas capacitações (se ela é problematizadora, crítica e promova a reflexão dos(as) 
participantes com possibilidade de transformação da realidade e das ações desenvolvidas no cotidiano), podendo se caracterizar enquanto Educação Permanente. Houve um relato que destacou que, a depender de como se conduza a Educação Continuada, pode haver desdobramentos na perspectiva de Educação Permanente.

Já a Educação Permanente, para os participantes, está intimamente ligada ao trabalho, respondendo suas necessidades e criando espaços/estratégias para refletir e atuar criticamente sobre seu cotidiano de forma coletiva.

Ainda sobre a Educação Continuada e Educação Permanente, os participantes consideraram que, para o planejamento e realização de ações educativas, independentemente se uma ou outra, é importante construir com as pessoas e não para a as pessoas. Ou seja, é importante incluir todos os sujeitos no desenvolvimento de uma ação educativa. Além disso, ainda sobre esta relação entre educação permanente e educação continuada, os participantes destacaram a necessidade de se incorporar as questões trazidas pela educação permanente no planejamento e realização de ações de educação continuada como, por exemplo, a preocupação para que as capacitações, mesmo as pontuais, tragam questões e casos sobre as realidades dos trabalhadores e sugiram mudança nos contextos mais diversos.

Para os participantes, o trabalho coletivo deve ser compreendido como um movimento solidário, em que os membros, apesar de se empenharem em ações diversas, olham para a mesma direção, sempre procurando relações entre o que estão fazendo, compartilhando avanços e desafios e propondo, em conjunto, estratégias e resoluções para enfrentamento dos problemas.

Vale ressaltar que, durante os debates nas oficinas, a dimensão do sujeito sempre esteve presente na perspectiva de compreender quem compõe o cenário do processo educativo (gestores, profissionais de saúde, sociedade civil, atores da universidade). Dessa forma, destacou-se, a partir da problematização com o grupo, que é importante que se compreenda quais as disputas, interesses e ideologias que estão em jogo, de modo a realizar as mediações possíveis para que se possa construir um processo de educação permanente transversal, participativo, autônomo e sustentável. 
Apesar dos conceitos que puderam ser identificados como coletivos, ou seja, conceitos que foram elaborados pela maioria ou quase totalidade do grupo, vale ressaltar questões pontuais que apareceram durante as discussões. Uma das participantes trouxe, por exemplo, a possibilidade de não haver um conceito fechado, mas sim dinâmico sobre educação. O que possibilitaria uma revisão constante pelo grupo. Outra questão pontual que pode ser observada na leitura dos relatórios, foi que alguns participantes tiveram dificuldade, durante os oito encontros, de diferenciar educação permanente e educação continuada, mesmo após os debates realizados nas rodas de conversa e a realização dos trabalhos em grupo.

Algumas questões foram trazidas pelos participantes como dúvidas ou provocações no sentido de promover a reflexão em relação aos conceitos relativos à educação: "Educação permanente e Educação Continuada concorrem entre si?", "Será que toda educação continuada é permanente?"; "O que acontece permanentemente é educação permanente?"; “A Educação permanente é compartilhar, é trocar conhecimentos?"; "Construir uma capacitação requer troca, compartilhamento de informações. Por isso uma capacitação pode ao mesmo tempo ter elementos de Educação Permanente e Educação Continuada?".

\subsection{Categoria: Dificuldades}

A questão geradora da análise sobre esta categoria foi: "Quais dificuldades, relacionadas ao trabalho ou a realização de determinadas ações educativas, foram relatadas pelo coletivo?". Aqui, pretendeu-se identificar dificuldades e desafios encontrados pelos trabalhadores na realização de suas ações no Departamento. Com isso, foi possível sugerir possíveis ações para a sua superação. Estas ações foram elencadas no item 4 desta dissertação, intitulado considerações finais.

O desafio atual relatado pelos participantes é o de capacitar os profissionais que compõem a Rede e faze-la funcionar como planejada. Para eles, a política de Educação Permanente está desarticulada das demais políticas 
de educação na saúde, além de as diretrizes da EP não estarem implementadas por completo no dia a dia dos serviços. Pelas experiências que possuem em atividades realizadas no território (estados brasileiros) há grande desconhecimento sobre Educação Permanente nessas localidades e, a ela, atribuem qualquer ação educativa realizada. Ao mesmo tempo, observa-se, nessas mesmas localidades, grande interesse sobre o tema.

Como desafios, foram trazidos alguns exemplos pelos participantes da Rede: o de tornar o SUS um espaço de formação de trabalhadores, bem como pensar em processos formativos que tenham como enfoque responder às necessidades de saúde da população. O reconhecimento e enfrentamento de um contexto no qual a política de EP está desarticulada das demais políticas de educação na saúde, além de as diretrizes da EP não estarem implementadas por completo no dia a dia dos serviços foram também mencionados.

Já sobre as reflexões sobre os processos de trabalho desenvolvidos no âmbito do Departamento de DST, Aids e Hepatites Virais, os participantes relatam que o planejamento e o monitoramento não refletem o significado do "fazer", daquilo que se faz realmente no dia a dia do trabalho. Para eles o DDAHV apresenta-se fragmentado e nem sempre é possível enxerga-lo como um todo. Em algumas áreas, não há compartilhamento de processos ou informações entre os colegas. Os processos de trabalho são enrijecidos e há carência de reuniões ou outros encontros que promovam compartilhamento de ideias, de demandas, de sugestões e de críticas. Há resistências individuais e problemas referentes a questões políticas e de gestão local. Ainda sobre os desafios relatados pelos participantes relativos à sua atuação no DDAHV, foram mencionados: importância/dificuldade em sistematizar as coisas que se faz, bem como se apropriar do que o outro sistematizou; a complexidade e necessidade de pensar no monitoramento e avaliação como uma ação transversal no Departamento; tornar a educação permanente o pilar da estruturação da linha de cuidado e reorganização da rede; necessidade de ampliar o olhar sobre a educação, para extrapolar as dimensões organizativas em relação aos processos educacionais e atuar numa perspectiva mais técnica e política.

De acordo com os participantes há uma dificuldade de comunicação e de construção com outras áreas do Departamento. Falta consenso entre os trabalhadores. Além disso, os participantes relatam que é preciso compreender 
melhor o contexto entendendo que ele é permeado por fragmentação, desarticulação entre as áreas, por centralização de demandas e que muitas decisões são tomadas de forma vertical, cima para baixo. No entanto, acreditam que é possível buscar meios de tornar as decisões mais horizontais com promoção de autonomia das trabalhadoras e dos trabalhadores. Ainda sobre a frágil articulação entre as áreas, uma participante chamou a atenção sobre o sentido de trabalho coletivo que é compreendido por muitos trabalhadores "como o trabalho em que as pessoas se reúnem, pensam juntas algumas ações e depois dividem tarefas entre si, sem ficar sabendo, depois desta reunião, o que cada um está fazendo". Ao contrário, ressalvou que trabalho coletivo deve ser compreendido como um movimento solidário, em que os membros, apesar de se empenharem em ações diversas, olham para a mesma direção, sempre procurando relações entre o que estão fazendo, compartilhando avanços e desafios e propondo, em conjunto, estratégias e resoluções para enfrentamento dos problemas

Os participantes concordam que a causa dos problemas apresentados é multifatorial.

Como dificuldade em relação à realização das ações educativas, os participantes destacam que a sustentabilidade deveria ser uma preocupação no momento de planejamento de uma ação educativa. Muitas ações, por não terem continuidade, não geram os impactos e resultados pretendidos. Este fato foi relatado pelos participantes que executam e acompanham ações educativas, sobretudo capacitações, voltadas aos profissionais de saúde do território.

\subsection{Categoria: Potencialidades}

A partir da questão "Quais potencias, relacionadas ao trabalho ou a realização de determinadas ações, foram relatadas pelo coletivo? ", foi possível identificar ações que pudessem destacar a educação na prática profissional dos participantes e, além disso, elencar possíveis características que deveriam ser valorizadas para que essas ações pudessem ser realizadas de forma coerente. 
Para os participantes, os encontros da Rede foram mencionados como algo que tem propiciado uma possível mudança institucional e que, se incorporado ao cotidiano do trabalho, pode gerar impactos interessantes nas ações que os trabalhadores que a compõe realizam no território. Foi discutido que a rede tem um papel que extrapola a Educação Permanente, promovido pelo pensar coletivamente e que possibilita conhecer como o outro trabalha, trabalhar com o outro. O Núcleo Educação (NE) foi mencionado como potencializador dessas ações, assumindo um importante papel junto às áreas na mediação e facilitação de processos voltados à gestão do trabalho.

O processo de planejamento do Departamento também foi mencionado como potência para a melhoria da gestão e da realização das atividades no trabalho, já que foi identificado como espaço que pode propiciar que as pessoas abordem o seu processo de trabalho e pensem em formas diferentes de realizar trocas uns com os outros, além de saberem o que cada área tem feito e/ou como tem percebido cada processo. O planejamento foi identificando como um lugar para discutir o processo de trabalho.

Os participantes também perceberam a importância de legitimar e fortalecer as estratégias locais (nos estados brasileiros) e considerar o território enquanto produtor de práticas potentes, apontando para a necessidade de criar estratégias que possam trazer isso à tona.

Além disso, os participantes identificaram ações educativas pontuais que sugerem um espaço para que os princípios e potencialidades que a educação permanente oferece possam ser desenvolvidos. Essas ações pontuais, cursos, poderiam ser remodelados e redefinidos como possíveis ferramentas de gestão como, por exemplo, o Curso Básico de Vigilância em Saúde, desenvolvido junto às outras áreas do DDAHV e a atores externos e o curso TELELAB, que atua diretamente em ações de padronização de procedimentos de bancada de laboratório. Para os participantes, as discussões sobre educação permanente têm contribuído para que começassem a identificar os espaços como espaços de ações produtoras de mudança.

Outro elemento que apareceu na fala dos participantes foi a relação do Departamento com os estados e municípios e as ações desenvolvidas que podem contribuir para potencializar as gestões locais. Foram citadas como exemplos as videoconferências com a rede de logística de medicamentos 
antirretrovirais sobre o Sistema de Controle Logístico de Medicamentos (SICLOM); videoconferências com a rede de serviços de sorologia/diagnóstico sobre o Sistema Logístico de Insumos Laboratoriais (SISLOGLAB), bem como encontros presenciais, em situações pontuais, com vistas à melhoria do processo logístico. Além disso foi mencionada a construção coletiva da linha de cuidado de Profilaxia Pós Exposição ao HIV (PEP) e as ações hoje realizadas nos estados cuja taxa de detecção do HIV é maior que a média nacional, como Amazonas, Rio de Janeiro, Rio Grande do Sul e Santa Catarina. Ações essas, elaboradas a partir do planejamento de um plano estadual de educação permanente em saúde.

\section{Considerações Finais}

Além dos debates provocados e promovidos pela Rede, foi possível extrair, a partir da análise dos relatórios, possíveis encaminhamentos e desdobramentos para potencializar esta estratégia e garantir, em certa medida, a melhoria na atuação dos trabalhadores deste Departamento. O primeiro deles, refere-se à sugestão de incluir os membros da Rede no processo de planejamento do Departamento, para que possam contribuir com o fortalecimento na capacidade de reflexão e de atuação destas trabalhadoras e destes trabalhadores frente aos mais diversos processos de trabalho. Além disso, sugeriu-se a ampliação da Rede, possibilitando a inserção de outros trabalhadores que tenham interesse em colaborar com o grupo.

Outros pontos também merecem destaque, como:

$\checkmark$ A necessidade de olhar mais para o planejamento para superar algumas das dificuldades enfrentadas, na perspectiva de harmonizar o máximo as possibilidades e as atividades;

$\checkmark$ A realização de um levantamento de percepções, obstáculos e soluções junto aos trabalhadores do Departamento, por mecanismos que preservem a identidade dos participantes;

$\checkmark$ A análise e compreensão das disputas, interesses e ideologias que estão em jogo, de modo a realizar as mediações possíveis para que se possa construir um processo de educação permanente transversal, participativo, autônomo e sustentável; 
$\checkmark$ A mobilização dos diversos atores para identificação das ações a comporem as Agendas de Educação Permanente em estados e municípios;

$\checkmark$ A possibilidade para a criação de grupos de trabalho nos territórios para o planejamento e execução desses planos de Educação Permanente;

$\checkmark$ A necessidade de qualificação profissional dos trabalhadores do Departamento em temáticas que estejam diretamente relacionadas à sua atuação profissional (destaque para cursos de Vigilância Epidemiológica, Gestão, Redação Oficial, SUS, dentre outros)

$\checkmark$ A necessidade de se desenvolver mecanismos de monitoramento e avaliação das ações desenvolvidas pelos trabalhadores do DDAHV nos territórios no intuito de compreender como estes contribuem para o aperfeiçoamento profissional dos/as cursistas e como estes aplicam e incorporam conhecimentos e habilidades no cotidiano de trabalho;

$\checkmark$ A realização de rodas de conversa com temáticas a serem propostas e de reuniões internas periódicas (na área) para discussão de fluxo de trabalho e processos e outras demandas que se fizerem necessárias sobre diversos temas relacionados à atuação do Departamento (DST, aids e HV)

$\checkmark$ A criação de mecanismos para tornar mais visível e mais institucionalizado o espaço da Rede para todo o Departamento, a fim de que todas e todos tenham noção clara do objetivo, da importância e do que é debatido e construído neste espaço;

$\checkmark$ Promoção de um encontro para uma apresentação formal sobre a rede com o intuito de sensibilizá-los acerca de sua importância e necessidade de haver mais fluidez e legitimidade institucional nos processos desencadeados pela mesma;

$\checkmark$ A necessidade de se rever o projeto da Rede conjuntamente para estabelecer novas estratégias e, possivelmente, novos objetivos;

$\checkmark$ A importância da sensibilização de dirigentes (Diretoria, coordenadores e gerentes) para a importância da Rede 
Colaborativa de Educação, para as Rodas de Conversa e outras ações educativas desenvolvidas no âmbito do DDAHV;

Este estudo apontou alguns caminhos e possíveis desdobramentos a partir da análise dos achados e dos resultados obtidos com a observação e participação nas rodas de conversa realizadas pela Rede Colaborativa de Educação Permanente.

Percebeu-se que, apesar de ser fluido e muitas vezes parecer evidente a compreensão de determinados conceitos relacionados à educação e trabalho, muitos participantes da Rede revelaram ideias contrárias ou mesmo contraditórias quando questionados em relação às suas práticas. Este fato ficou evidenciado não apenas pela pesquisadora, mas pelo grupo.

Percebeu-se, ainda, que os conceitos de educação permanente e educação continuada são comumente associados, gerando práticas muitas vezes conservadoras como, por exemplo, ações pontuais de educação, cursos e capacitações, prejudicando assim, a ampliação do debate sobre práticas contínuas e processos de transformação das realidades a partir do que hoje entendemos como educação permanente. Constatou-se, neste caso, a necessidade de uma ampliação no debate sobre as contribuições que são possíveis identificar nessas duas modalidades de educação e que, sendo complementares podem, uma, contribuir a implantação da outra.

Percebe-se que as discussões promovidas pela e na Rede Colaborativa de Educação proporcionaram, ao grupo, a oportunidade de iniciar um processo coletivo de construção de um fazer trabalho. Aqui, não apenas do trabalho formal na instituição, mas, também, de pensar suas razões, seus métodos e seus desdobramentos.

A Rede revelou-se um espaço de garantia de diálogo dentro da instituição e oportunizou grande troca de experiências entre trabalhadores e trabalhadoras antes isolados em suas áreas no DDAHV. 


\section{Referências}

AFONSO, M. L.; ABADE, F. L. Para reinventar as rodas: rodas de conversa em direitos humanos. Belo Horizonte: RECIMAM, 2008.

ALMEIDA, Elton Carlos de. Pesquisa-ação com alunos do curso de graduaçãoem enfermagem sobre o processo de doação de órgãos. Ribeirão Preto, 2015.

AMARAL, J. F. J. Como fazer uma pesquisa bibliográfica. Disponível em: $<$ https://cienciassaude.medicina.ufg.br/up/150/o/Anexo_C5_Como_fazer_pesq uisa_bibliografica.pdf $>$. Acesso em 3 de ago de 2016.

BRASIL. Ministério da Saúde. Secretaria Executiva. Núcleo Técnico da Política Nacional de Humanização. HumanizaSUS: política nacional de humanização. Brasília, 2003.

BRASIL. Ministério da Saúde. Portaria o 1.996, de 20 de Agosto de 2007. Dispõe sobre as diretrizes para a implementação da Política Nacional de Educação Permanente em Saúde.

BRASIL. Ministério da Saúde. Política Nacional de Educação Popular em Saúde. Institui a Política Nacional de Educação Popular em Saúde no âmbito do Sistema Único de Saúde (PNEPS-SUS). Brasília, 2013.

CAMPOS, G.W.S. 2000. Um método para análise e co-gestão de coletivos: a constituição do sujeito, a produção de valor de uso e a democracia em instituições: o método da roda. São Paulo: HUCITEC, 2000.

CAPRA, F. Alfabetização ecologia: o desafio para a educação do século 21. In: TRIGUEIRO, A. (Coord.). Meio ambiente no século 21: 21 especialistas falam da questão ambiental nas suas áreas de conhecimento. 3. ed. Rio de Janeiro: Sextante, 2003. p. 18-33.

CECCIM, R.B. Educação Permanente em Saúde: desafio ambicioso e necessário. Interface - Comunicação, Saúde, Educação, v.9, n.16, p.161-177, set.2004/fev.2005. Disponível em: http://www.scielo.br/pdf/icse/v9n16/v9n16a13.pdf >. Acesso em Out. 2015.

CELLARD, A. A análise documental. In: POUPART, J. et al. A pesquisa qualitativa: enfoques epistemológicos e metodológicos. Petrópolis: Vozes, 2008.

CHAMPAGNE ET AL. A Avaliação no Campo da Saúde: conceitos e métodos. In: BROUSSELE ET AL.(orgs.). Avaliação: conceitos e métodos. Rio de Janeiro: Editora Fiocruz, 2011a.

CHAMPAGNE ET AL. Modelizar Intervenções. In: BROUSSELE ET AL.(orgs.). Avaliação: conceitos e métodos. Rio de Janeiro: Editora Fiocruz, 2011 b. 
DENZIN, Norman K.; LINCOLN, Yvonna. Adisciplina e a pratica da pesquisa qualitativa. In: DENZIN, Norman K.; LINCOLN, Yvonna(orgs). Planejamento da pesquisa qualitativa: teorias e abordagens. 2 ed. Porto Alegre:ARTMED, 2006.

DONATO, A. F.; ROSENBURG, C. P. Algumas idéias sobre a relação Educação e Comunicação no âmbito da Saúde. Saúde e Sociedade, São Paulo, p.18-25, dez. 2003.

FREIRE P. Pedagogia do oprimido. 17a ed. Rio de Janeiro: Paz e Terra; 1970 . Educação e mudança. Rio de Janeiro: Paz e Terra, 26 ed., 2002. . Educação como prática da liberdade. Rio de Janeiro: Paz e Terra, 2011. Pedagogia da Autonomia, São Paulo: Paz e Terra, 1996. Autores Associados: Cortez, 1989.

FIGUEIRÊDO, A. A. F.; QUEIROZ. T. N. A utilização das rodas de conversa como metodologia que possibilita 0 diálogo. Disponível em: <http://www.fazendogenero.ufsc.br/10/resources/anais/20/1384186533_ARQUI VO_AlessandraAniceto.pdf>. Acesso em Jul 2016.

GODOY, A. S. Pesquisa Qualitativa: tipos fundamentais. Revista de Administração de Empresas. São Paulo, v. 35, n.3, p, 20-29, Mai./Jun. 1995.

GOMES, R. Análise de dados em pesquisa qualitativa. In: MINAYO, M. C. (org.). Pesquisa Social: Teoria, método e criatividade. 18 ed. Petrópolis: Vozes, 2001. Cap. 4. p. 67-80.

GONÇALVES, Antonio Sérgio; GUARÁ, Isa Maria F. Rosa. Redes de proteção social na comunidade. In: GUARÁ, Isa Maria F. Rosa. Redes de proteção social. Abrigos em movimento. 2010.p. 11-20.

HEIDEMANN, I.T.S.B. A Promoção da saúde e a concepção dialógica de Freire: possibilidades de sua inserção e limites nos processos de trabalho das equipes de saúde da família. 2006. Tese - Escola de Enfermagem de Ribeirão Preto. Universidade de São Paulo, Ribeirão Preto.

LUSSI, C.; MARINUCCI, R. Notas sobre trabalho em rede. 2007. Disponível em: $<$ http://www.csem.org.br/pdfs/notas_sobre_trabalho_em_rede.pdf >. Acesso em: jul de 2016.

MÉLLO, R. P. et al. Construcionismo, práticas discursivas e possibilidades de pesquisa. Psicologia e Sociedade, v.19, n.3, p. 26-32, 2007.

MERHY, E.E.; FEUERWERKER, L.C.M; CECCIM, R.B.. Educación Permanente en Salud - una estrategia para intervenir en la micropolítica del trabajo en salud. Salud Colectiva, Buenos Aires, 2(2): 147-160, Maio - Agosto, 2006. Disponível em: http://www.scielo.org.ar/pdf/sc/v2n2/v2n2a04.pdf. Acesso em out de 2015. 
MINAYO, M. C.; SANCHES, O. Quantitativo-Qualitativo: Oposição ou complementaridade?. Cadernos de Saúde Pública, Rio de Janeiro, v. 9, n. 3, p 239-262, jul-set, 1993.

PEDUZZI M., et al. Atividades educativas de trabalhadores na atenção primária: concepções de educação permanente e de educação continuada em saúde presentes no cotidiano de Unidades Básicas de Saúde em São Paulo. Interface - Comunicação, Saúde, Educação, Botucatu, v. 13, n. 30, p. 121-134, 2009.

YIN, R. K. Estudo de caso - planejamento e métodos. (2 Ed). Porto Alegre: Bookman. 2001

VENTURA, M. M.. O estudo de caso como modalidade de pesquisa. Revista Pedagogia Médica. Rio de Janeiro. 20(5): 383-386, setembro, 2007. Disponível em:

$<$ http://unisc.br/portal/upload/com_arquivo/o_estudo_de_caso_como_modalida de_de_pesquisa.pdf>. Acesso em Ago de 2016. 


\section{APÊNDICES}

Apêndice 1 - Quadro de resultados por categorias de análise 


\section{APÊNDICES}

Apêndice 1 - Quadro de resultados por categorias de análise

\begin{tabular}{|c|c|c|c|}
\hline Categorias & Subcategoria & Ideias Centrais & Oficina \\
\hline $\begin{array}{l}\text { Conceitos: } \\
\text { Que } \\
\text { conceitos } \\
\text { sobre } \\
\text { educação (ou } \\
\text { similar) }\end{array}$ & Educação & Quadro, p 3, palavras priorizadas na p 4 & 1 \\
\hline $\begin{array}{l}\text { vieram do } \\
\text { grupo? Que } \\
\text { conceitos } \\
\text { sobre } \\
\text { educação (ou } \\
\text { similar) foram } \\
\text { construídos }\end{array}$ & & $\begin{array}{l}\text { Uma das participantes trouxe a possibilidade de não haver um conceito } \\
\text { fechado, mas sim dinâmico sobre educação. }\end{array}$ & I \\
\hline $\begin{array}{c}\text { coletivament } \\
\text { e? Como a } \\
\text { educação } \\
\text { aparece nos } \\
\text { encontros? }\end{array}$ & & $\begin{array}{l}\text { A educação é uma ferramenta transversal, que se conseguir elaborar um plano } \\
\text { consistente torna-se sustentável, favorece a mudança de prática e induz a } \\
\text { aceitabilidade. Vem sendo discutida em SC num processo participativo, de } \\
\text { confiança e expectativa positiva. }\end{array}$ & I SC \\
\hline
\end{tabular}




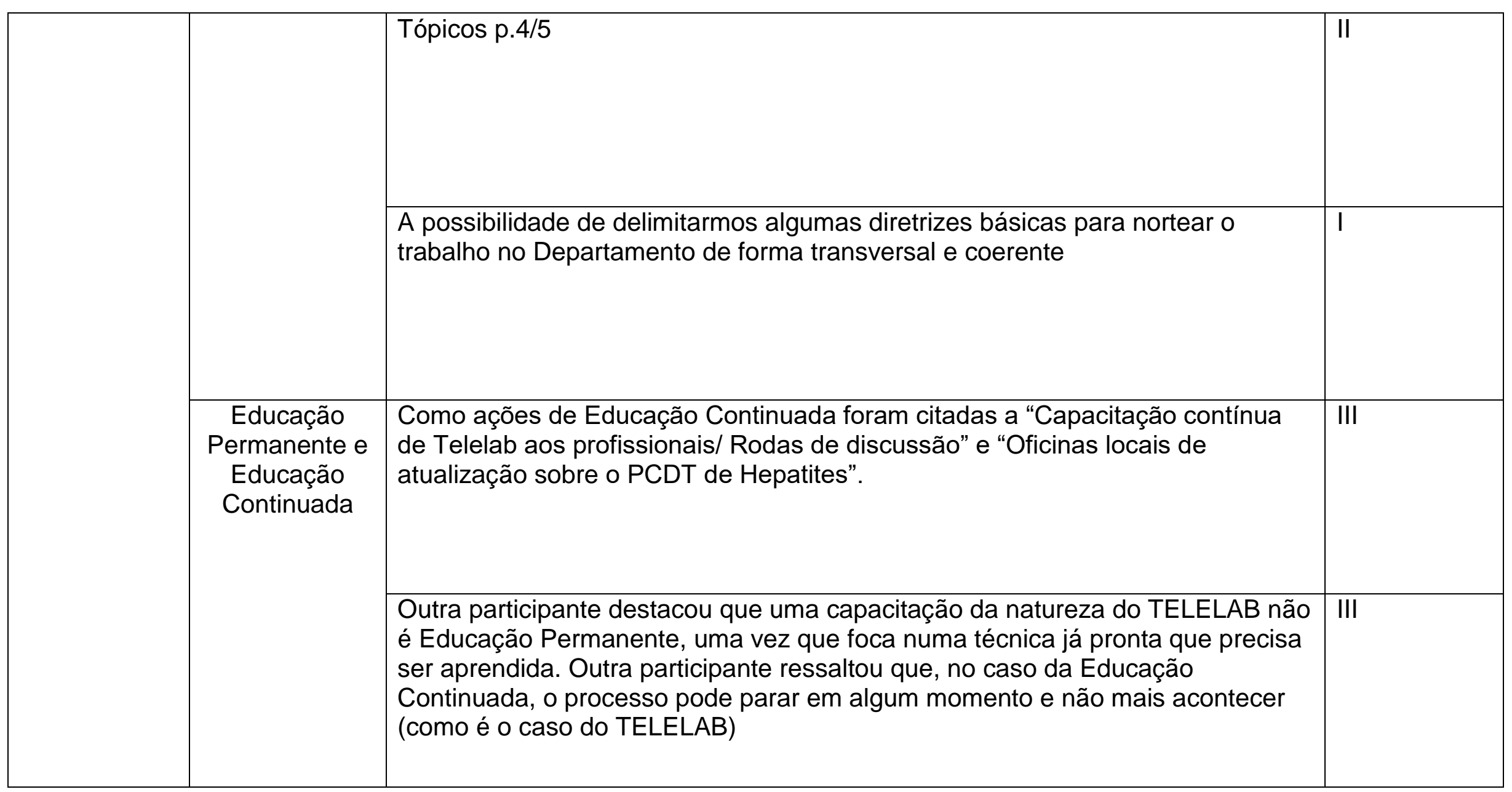




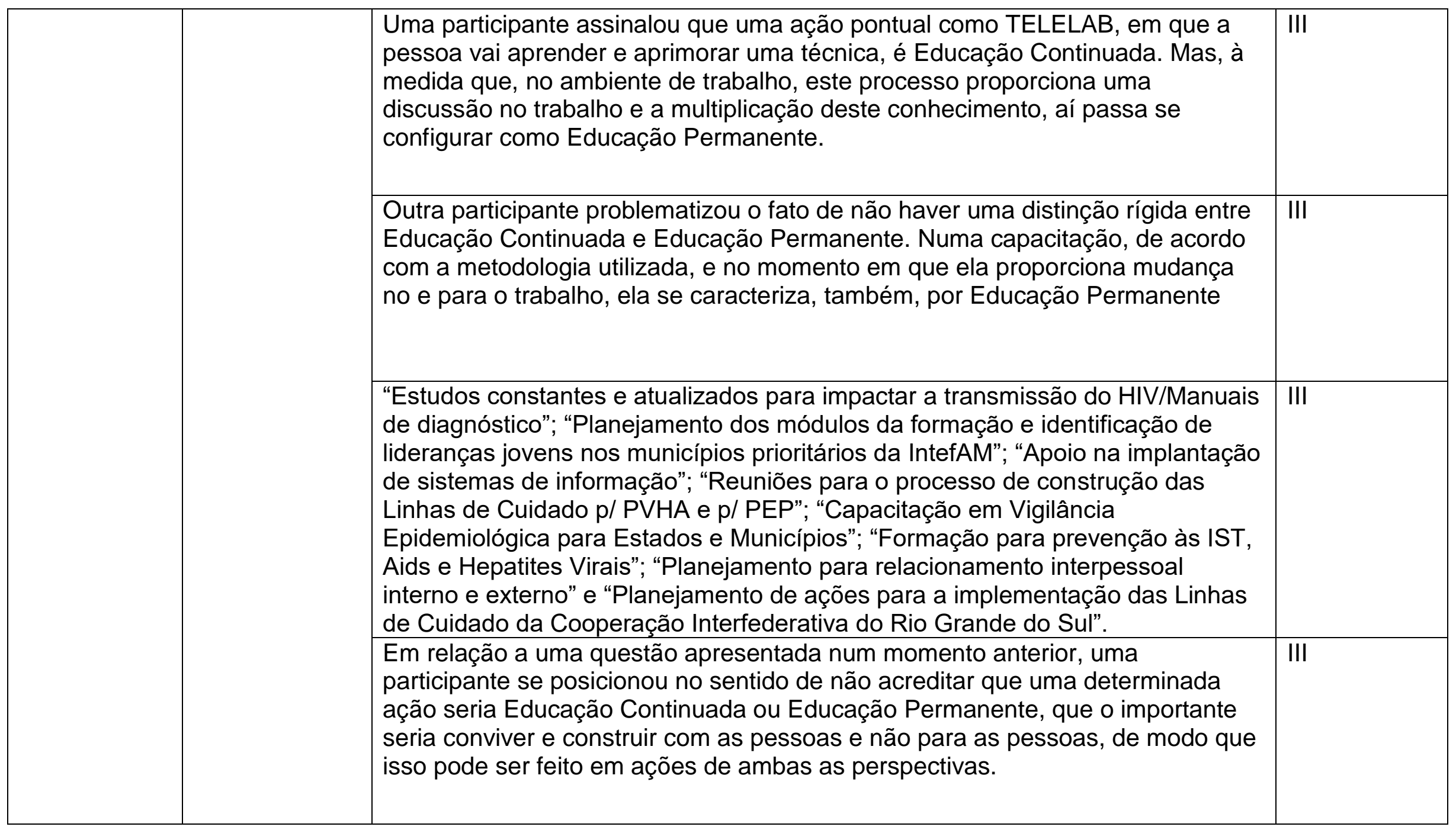




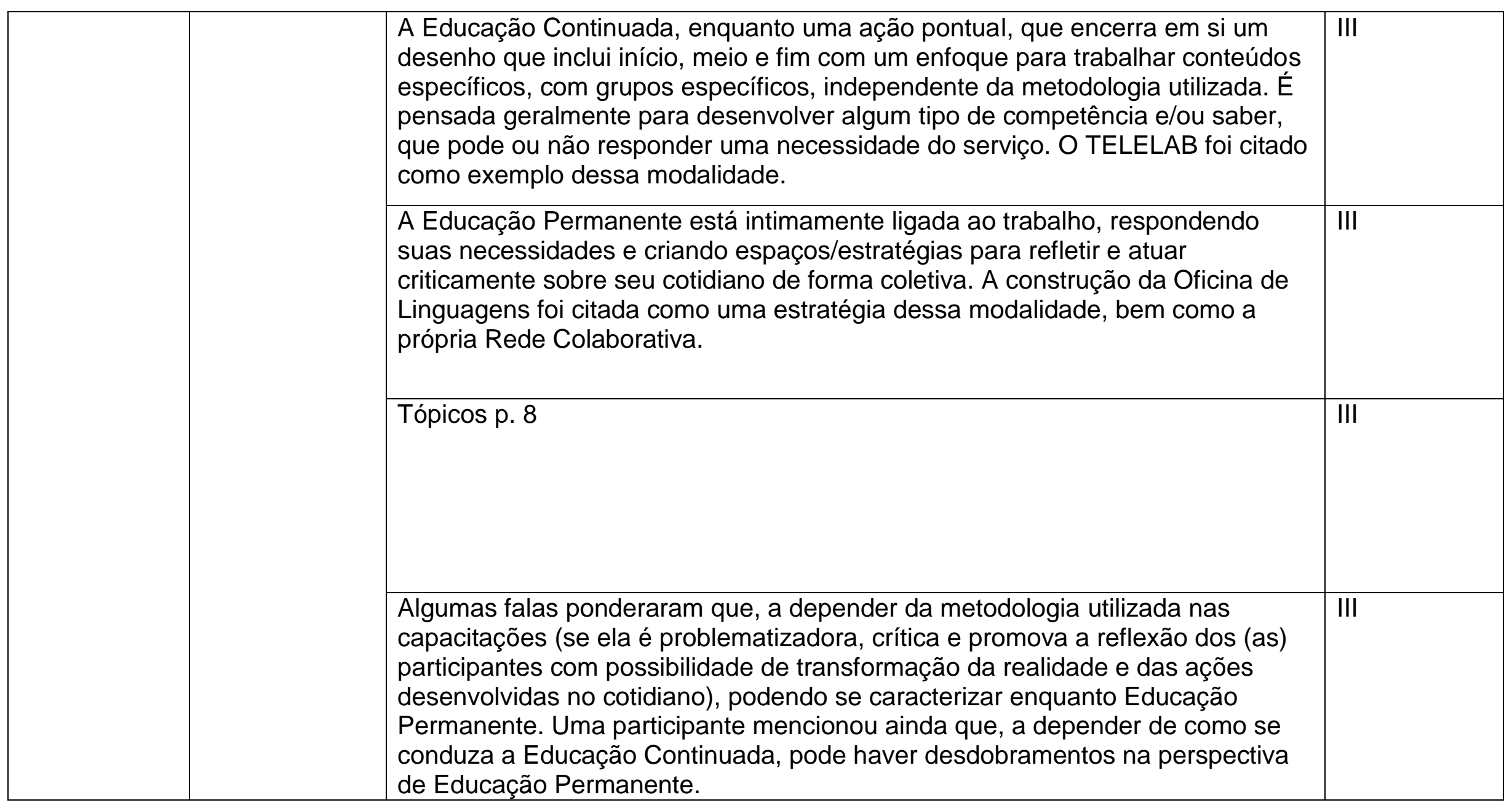




\begin{tabular}{|c|c|c|}
\hline \multirow[t]{9}{*}{$\begin{array}{l}\text { Dificuldades: Quais } \\
\text { dificuldades, relacionadas ao } \\
\text { trabalho ou a realização de } \\
\text { determinadas ações, foram } \\
\text { relatadas pelo coletivo nos } \\
\text { encontros realizados? }\end{array}$} & $\begin{array}{l}\text { Um exemplo foi o de tornar o SUS um espaço de formação de trabalhadoras } \\
\text { (es), bem como pensar em processos formativos que tenham como enfoque } \\
\text { responder às necessidades de saúde da população. O reconhecimento e } \\
\text { enfrentamento de um contexto no qual a política de EP está desarticulada das } \\
\text { demais políticas de educação na saúde, além de as diretrizes da EP não } \\
\text { estarem implementadas por completo no dia a dia dos serviços foram } \\
\text { mencionados. Ainda há a escassez e a má distribuição de médicos, bem como } \\
\text { as diversas modalidades de contratação das (os) profissionais de saúde nesse } \\
\text { panorama. }\end{array}$ & I \\
\hline & $\begin{array}{l}\text { Pouca participação do município de Brusque e Balneário Camboriú. Observam- } \\
\text { se também resistências individuais e problemas referentes a questões políticas } \\
\text { e de gestão local. }\end{array}$ & I SC \\
\hline & $\begin{array}{l}\text { O desafio atual é o de capacitar os profissionais e fazer a rede funcionar como } \\
\text { planejada. }\end{array}$ & I AM \\
\hline & $\begin{array}{l}\text { Não foi construído um plano de Educação Permanente na InterfAM. Além disto, } \\
\text { pode não haver conhecimento sobre Educação Permanente nos municípios, ou } \\
\text { até mesmo a percepção de que o que está sendo discutido faz parte da } \\
\text { Educação Permanente, mas mesmo assim ela está inserida em diversas ações. }\end{array}$ & I AM \\
\hline & As ações dos diversos comitês da InterfAM não estão conversando entre si & I AM \\
\hline & Tópicos da p 11 & I AM \\
\hline & $\begin{array}{l}\text { O desconhecimento de um registro sobre a análise da capacidade da rede } \\
\text { assistencial instalada no estado; Comunicação e consenso quando se trata de } \\
\text { quais estratégias utilizar para implementação da Linha de Cuidado construída } \\
\text { em } 2014 \text {. }\end{array}$ & I RS \\
\hline & Tópicos p. 2 & II AM \\
\hline & $\begin{array}{l}\text { Alguns desafios foram mencionados: importância/dificuldade em sistematizar as } \\
\text { coisas que se faz, bem como se apropriar do que o outro sistematizou; a } \\
\text { complexidade e necessidade de pensar no monitoramento e avaliação como } \\
\text { uma ação transversal no Departamento; tornar a educação permanente o pilar } \\
\text { da estruturação da linha de cuidado e reorganização da rede; necessidade de }\end{array}$ & II \\
\hline
\end{tabular}




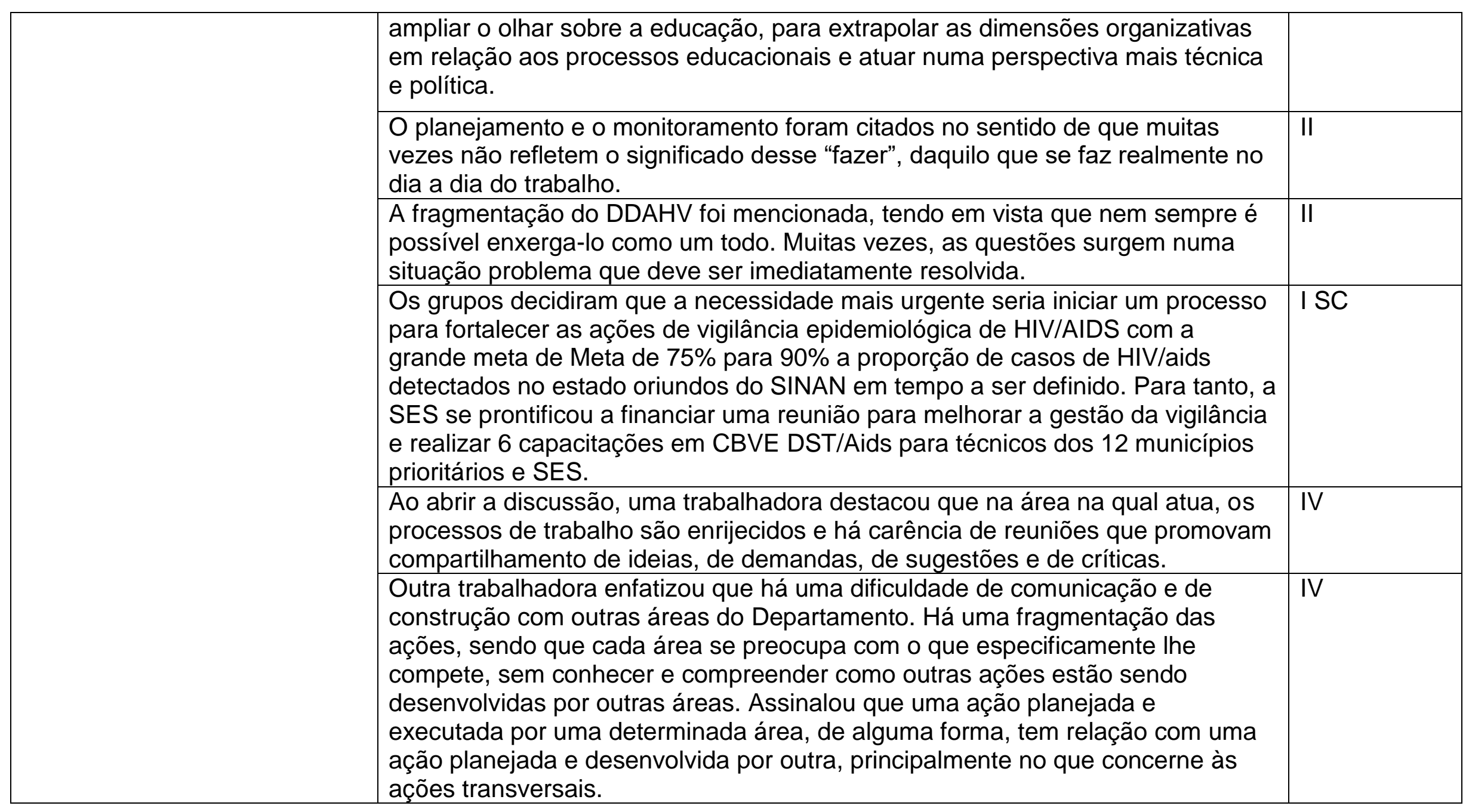




\begin{tabular}{|c|c|c|}
\hline & $\begin{array}{l}\text { Outro participante deu continuidade à reflexão acima, assinalando que é preciso } \\
\text { compreender melhor o nosso contexto. Sabe-se que ele é permeado por } \\
\text { fragmentação, desarticulação entre as áreas, por centralização de demandas e } \\
\text { que muitas decisões são tomadas de cima para baixo. Mas, que pode se buscar } \\
\text { meios de como tornar as decisões mais horizontais com promoção de } \\
\text { autonomia das trabalhadoras e dos trabalhadores. }\end{array}$ & IV \\
\hline & $\begin{array}{l}\text { Foi relatado que, em algumas áreas, não há compartilhamento de processos ou } \\
\text { informações entre os (as) colegas. }\end{array}$ & V \\
\hline & O consenso que se chegou a esse respeito foi o fato de a causa ser multifatorial & VII \\
\hline & $\begin{array}{l}\text { Desafio apontado foi o fato de ampliar a participação das pessoas na rede, } \\
\text { provocando o desejo de estar ali. Falar sobre o que é a rede, legitimar esse } \\
\text { espaço, sensibilizar, conquistar, apresenta-la enquanto espaço potente de e } \\
\text { sobre o trabalho }\end{array}$ & VII \\
\hline \multirow{6}{*}{$\begin{array}{l}\text { Potencialidades: Quais } \\
\text { potencias, relacionadas ao } \\
\text { trabalho ou a realização de } \\
\text { determinadas ações, foram } \\
\text { relatadas pelo coletivo nos } \\
\text { encontros realizados? }\end{array}$} & $\begin{array}{l}\text { O território enquanto produtor de práticas potentes foi mencionado, apontando- } \\
\text { se para a necessidade de criar estratégias para trazer isso à tona }\end{array}$ & I \\
\hline & $\begin{array}{l}\text { A vigilância epidemiológica foi priorizada para ser ferramenta de gestão para } \\
\text { direcionar as ações, e os indicadores prioritários no Estado }\end{array}$ & ISC \\
\hline & $\begin{array}{l}\text { Tanto a linha de cuidado de PEP quanto suas capacitações foram construídas } \\
\text { conjuntamente. }\end{array}$ & I AM \\
\hline & $\begin{array}{l}\text { Observou-se uma recente "aceitação" da Coordenação Estadual em discutir } \\
\text { estratégias de Educação Permanente além da proposta apresentada pela Rede } \\
\text { de Governos - UFRGS }\end{array}$ & I RS \\
\hline & $\begin{array}{l}\text { Materiais educativos foram elaborados e disponibilizados para o estado, e } \\
\text { brevemente serão convertidos em vídeo-aulas, com objetivo de auxiliar a gestão } \\
\text { estadual e municipal no processo de formação e atualização dos profissionais. }\end{array}$ & I RS \\
\hline & $\begin{array}{l}\text { Em Santa Catarina estas discussões vêm ocorrendo no âmbito de cada Câmara } \\
\text { Técnica (CT). Foram definidas três CT: de Assistência e Linhas de cuidado; } \\
\text { Vigilância e pesquisa; Prevenção. Com os três grupos se reúnem para decidir }\end{array}$ & ISC \\
\hline
\end{tabular}




\begin{tabular}{|c|c|c|}
\hline & $\begin{array}{l}\text { juntos, é possível identificar nas discussões os pontos em comum que } \\
\text { atenderão as necessidades comuns, ficando acordado que todas as propostas } \\
\text { de educação farão parte do Plano de Educação Permanente do Estado. }\end{array}$ & \\
\hline & $\begin{array}{l}\text { Destacou, dentre as ações realizadas na área, a elaboração do Curso Básico } \\
\text { de Vigilância em Saúde junto às outras áreas do DDAHV e a atores externos. } \\
\text { Lembrou, também, que alguns (mas) técnicos (as) já fazem cursos de pós- } \\
\text { graduação em instituições de ensino. }\end{array}$ & VI \\
\hline & $\begin{array}{l}\text { A representante da área de logística ressaltou que este processo de diálogo e } \\
\text { elaboração de propostas junto à sua equipe foi algo inovador e bem produtivo. } \\
\text { Os seus colegas acolheram bem esta inciativa. }\end{array}$ & VI \\
\hline & $\begin{array}{l}\text { Compartilhou, também, algumas ações que já são realizadas junto aos Estados } \\
\text { e Municípios e que pretendem dar continuidade, que são as: videoconferências } \\
\text { com a rede de logística de medicamentos antirretrovirais sobre o SICLOM; } \\
\text { videoconferências com a rede de serviços de sorologia/diagnóstico sobre o } \\
\text { SISLOGLAB, bem como encontros presenciais, em situações pontuais, com } \\
\text { vistas à melhoria do processo logístico }\end{array}$ & VI \\
\hline \multirow[t]{6}{*}{$\begin{array}{l}\text { Encaminhamentos: } \\
\text { Sugestões e Propostas do } \\
\text { coletivo em relação ao } \\
\text { trabalho e educação. }\end{array}$} & $\begin{array}{l}\text { É importante que se compreenda quais as disputas, interesses e ideologias que } \\
\text { estão em jogo, de modo a realizar as mediações possíveis para que se possa } \\
\text { construir um processo de educação permanente transversal, participativo, } \\
\text { autônomo e sustentável }\end{array}$ & I \\
\hline & $\begin{array}{l}\text { A importância de legitimar e fortalecer as estratégias locais foi reafirmada em } \\
\text { muitos momentos da discussão. }\end{array}$ & I \\
\hline & Tópicos na p 6 e 7 & \\
\hline & $\begin{array}{l}\text { Ficou definido que será instituído um Grupo Condutor de educação permanente, } \\
\text { composto por } 2 \text { técnicos de cada CT e de cada município. }\end{array}$ & I SC \\
\hline & Tópicos na p 11 & \\
\hline & $\begin{array}{l}\text { "O que a trabalhadora vai fazer na Rede Colaborativa", foi sugerida a iniciativa } \\
\text { de criar mecanismos para tornar mais publicizado e mais institucionalizado o } \\
\text { espaço da Rede para todo o Departamento, a fim de que todas e todos tenham }\end{array}$ & IV \\
\hline
\end{tabular}




\begin{tabular}{|l|l|l|}
\hline & $\begin{array}{l}\text { noção clara do objetivo, da importância e do que é debatido e construído neste } \\
\text { espaço. }\end{array}$ & \\
\hline & $\begin{array}{l}\text { Uma participante propôs que se deve construir com todo coletivo da Rede } \\
\text { Colaborativa, já nos encontros iniciais de 2016, estratégias para maior } \\
\text { legitimação de seu papel e de suas contribuiçóes para o DDAHV }\end{array}$ & IV \\
\hline $\begin{array}{l}\text { Foi proposto que uma das estratégias seria envolver mais as trabalhadoras e os } \\
\text { trabalhadores, no sentido de somar potencialidades à Rede. A ideia é que a } \\
\text { própria rede possa contribuir com o fortalecimento na capacidade de reflexão e } \\
\text { de atuação destas trabalhadoras e destes trabalhadores frente aos mais } \\
\text { diversos processos de trabalho. Outra partícipe destacou, que dentre estes } \\
\text { processos de trabalho, merecem maior reflexão os de planejamento, } \\
\text { monitoramento e avaliação. }\end{array}$ & & \\
\hline $\begin{array}{ll}\text { Estratégias para o fortalecimento da Tópicos Rede p 3 } \\
\text { O grupo destacou a importância da regularidade de acontecimento dessas } \\
\text { ações. É importante manter a periodicidade. }\end{array}$ & IV \\
\hline $\begin{array}{ll}\text { 50 Oficina, planos para 2016, encaminhamentos. } \\
\text { Como encaminhamento deste encontro ficou para que os atores, em suas } \\
\text { respectivas áreas, mobilizassem suas respectivas equipes para identificação } \\
\text { destas ações a comporem a Agenda de Educação Permanente de 2016. }\end{array}$ & V/VI \\
\hline $\begin{array}{l}\text { A representante da Coordenação de Logística enfatizou que se reuniu com a } \\
\text { coordenadora e outros integrantes de sua área, os quais sugeriram a realização } \\
\text { de cursos de Excel Avançado e de Redação, devido à necessidade de } \\
\text { aperfeiçoamento na utilização do programa 'Excel' para aferição de dados e na } \\
\text { escrita de documentos oficiais, respectivamente. }\end{array}$ & VI \\
$\begin{array}{l}\text { A realização de rodas de conversa com temáticas a serem propostas como } \\
\text { Logística, SICLOM e de reuniões internas periódicas (na área) para discussão } \\
\text { de fluxo de trabalho e processos e outras demandas que se fizerem } \\
\text { necessárias. }\end{array}$ & VI \\
\hline
\end{tabular}




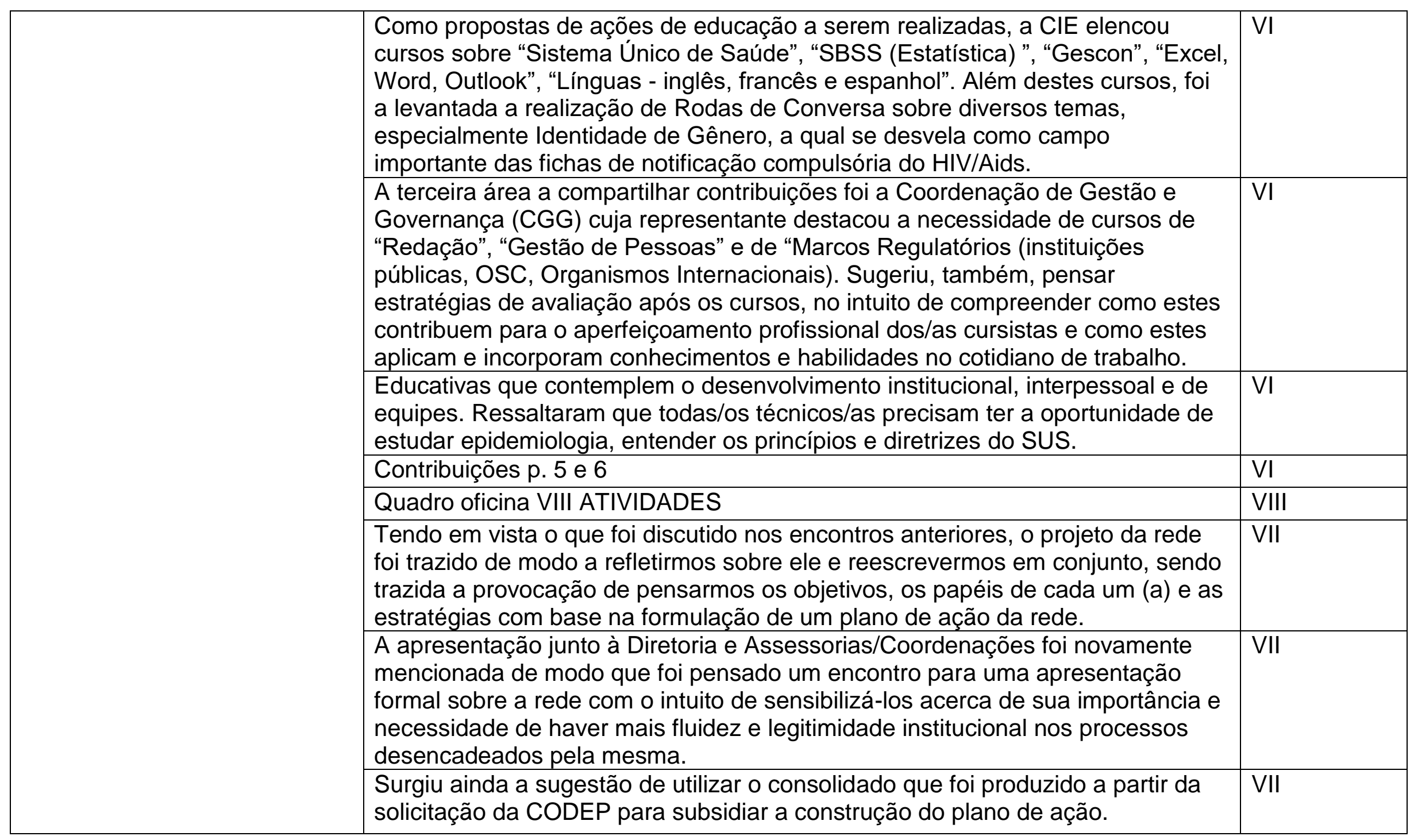




\begin{tabular}{|l|l|l|}
\hline & $\begin{array}{l}\text { Compreendendo que a Rede está em outro momento, já tendo avançado em } \\
\text { muitos aspectos das práxis da Educação, Educação Permanente e Educação } \\
\text { Continuada, optou-se por realizar a revisão do projeto original junto com o grupo }\end{array}$ & VII \\
& $\begin{array}{l}\text { Na discussão também foi mencionada a necessidade de olhar mais para o } \\
\text { planejamento para superar algumas das dificuldades enfrentadas, na } \\
\text { perspectiva de harmonizar o máximo as possibilidades, as atividades, etc. }\end{array}$ & VII \\
\hline $\begin{array}{l}\text { Realizar um levantamento de percepções, obstáculos e soluções junto aos (às) } \\
\text { técnicos (as) do Departamento, por mecanismos que preservem a identidade } \\
\text { dos (as) participantes. }\end{array}$ & VII \\
\hline & Encaminhamentos p. 5 & VII \\
\hline
\end{tabular}

Fonte: Elaboração Própria, 2016. 
Apêndice 2 - Artigo de revisão de literatura submetido à revista Interface.

\title{
A trajetória da Educação Popular em Saúde no Brasil
}

\section{Resumo}

A Educação Popular tem um papel importante na redefinição de práticas sociais de diversos campos do conhecimento. Ela estimula formas coletivas de aprendizado e investigação buscando, a partir da participação popular e da análise crítica sobre a realidade, um redirecionamento da vida social. A institucionalização da Política Nacional de Educação Popular em Saúde é dada por um conceito de horizontalidade, onde a política não é feita "para" o povo, e sim "com" o povo. Em seu percurso na história, foi se tornando uma referencial importante para os movimentos sociais e coletivos comprometidos com a transformação social, bem como para gestões que apresentam a ampliação da democracia e do protagonismo da sociedade civil como princípios básicos de suas políticas. O modelo de atenção vigente ainda não permite que estas práticas sejam totalmente legitimadas no âmbito do SUS.

Palavras chave: Educação Popular, Educação Popular em Saúde, Educação em Saúde.

\begin{abstract}
The popular education plays an important role in redefining social practices in many knowledge fields. It stimulates colective forms of learning and investigation, aiming to redirect social life through popular participation and critical analysis of the reality.

The institutionalization of the National Policy on Popular Health Education is based on horizontal concepts, where the policy isn't made "for" the people, but "with" the people. In its course in history, it has become an important landmark for social movements and collectives commited with social transformation, and also for administrations where the widening of democracy and the protagonism of civil society are the basic principles behind their policies. The current healthcare model does not allow these practices to be totally legitimated in the Unified Health System - SUS.
\end{abstract}

Keywords: Popular education, Popular education in health, education in health.

\section{Resumo}

La Educación Popular tiene un papel importante en la redefinición de las prácticas sociales en diversos campos del conocimiento. Estimula formas colectivas de aprendizaje e investigación buscando, a partir de la participación popular y del análisis crítica sobre la realidad, una otra dirección de la vida social. La institucionalización de la Política Nacional de Educación Popular en Salud es dada por un concepto de horizontalidad, donde la política no es hecha "para" el pueblo, y sí "con" el pueblo. En su recorrido por la historia, fue haciéndose una referencia importante para los movimientos sociales y colectivos comprometidos con la transformación social, así como para gestiones que presentan la ampliación de la democracia y del protagonismo de la sociedad civil 
como principios básicos de sus políticas. El modelo de atención vigente aún no permite que estas prácticas sean totalmente legitimadas en el ámbito del SUS.

Palabras clave: Educación Popular, Educación Popular en Salud, Educación en Salud.

\section{Apresentação}

As discussões sobre Educação Popular no Brasil e na América Latina tiveram seu início na década de 50 . Um de seus maiores representantes foi o educador brasileiro Paulo Freire, que acreditava e defendia uma educação voltada à autonomia e emancipação dos sujeitos. Para ele, dever-se-ia atribuir significativo valor ao senso comum, trazendo os setores populares em sua prática cotidiana, problematizando-o. ${ }^{1}$ A valorização do saber e valores do educando permitem que ele se sinta "em casa" e mantenha sua iniciativa. Neste sentido, não se reproduz a passividade usual dos processos pedagógicos tradicionais. Na Educação Popular, não basta que o conteúdo discutido seja revolucionário se o processo de discussão se mantém verticalizado, de cima para baixo. ${ }^{2}$

A Educação Popular estimula formas coletivas de aprendizado e investigação buscando, a partir da participação popular (individual ou em grupo) e da análise crítica sobre a realidade, um redirecionamento da vida social. Enfatiza não o processo de transmissão de conhecimento, mas a ampliação dos espaços de interação cultural e negociação entre os diversos atores envolvidos em determinado problema social, para a construção compartilhada do conhecimento e da organização política necessários à sua superação. Prioriza a relação com os movimentos sociais por serem expressão mais elaborada dos interesses e da lógica dos setores subalternos da sociedade, cuja voz é usualmente desqualificada nos diálogos e negociações. ${ }^{2}$

Para o setor saúde a participação histórica no movimento da Educação Popular foi marcante na criação de um movimento de profissionais que busca romper com a tradição autoritária e normatizadora da relação entre os serviços de saúde e a população, reorientando as práticas ali executadas e contribuindo na superação do biologicismo, autoritarismo do doutor, desprezo pelas iniciativas do doente e seus familiares e da imposição de soluções técnicas restritas para problemas sociais globais que dominam a medicina atual. ${ }^{2}$

Considerando seu histórico ela se apresenta como um caminho capaz de contribuir com metodologias, tecnologias e saberes para a constituição de novos sentidos e práticas para o Sistema Único de Saúde (SUS). Interage não apenas com a educação em saúde, mas no cuidado, na gestão, na formação e na participação social em saúde. ${ }^{3}$

\section{Trajetória da Educação Popular em Saúde no Brasil}

A trajetória das ações de educação em saúde no Brasil tem suas raízes nas primeiras décadas do século XX. A partir da década de 1940, as campanhas sanitárias e a expansão da medicina preventiva apresentavam estratégias de educação em saúde autoritárias, tecnicistas e biologicistas, tornando em que as classes populares eram vistas e tratadas como passivas e incapazes de iniciativas próprias. Contudo, esse cenário se modificou ao longo do tempo e, no 
Brasil, a partir da década de 1950 a Educação Permanente começou a se estruturar como corpo teórico e prática social. ${ }^{4}$

Entre os anos de 1950 e 1960, a Educação Popular foi constituída a partir de experiências entre intelectuais e as classes populares, desencadeando iniciativas de alfabetização, contrapondo o modelo dominante e trabalhando a visão crítica do mundo para que jovens e adultos pudessem construir seus caminhos com autonomia e alteridade, na perspectiva da emancipação social, humana e material. ${ }^{2-3} \mathrm{Na}$ mesma época, destacou-se o trabalho da Universidade de Recife no que se refere a qualificação e sistematização da Educação Popular impulsionando a promoção de várias experiências no campo da alfabetização e da cultura popular a partir do trabalho desenvolvido por vários professores, incluindo Paulo Freire. ${ }^{2}$

Durante o Golpe Militar em 1964, inicia-se no país um período de repressão e deteriorização da saúde da população. Assim, a EP assume o papel de resistência ao regime ditatorial, inspirando o surgimento e o desenvolvimento de inúmeras experiências educativas, não apenas no Brasil, mas, em toda América Latina. $O$ governo militar criou contraditoriamente condições para a emergência de uma série de experiências de educação em saúde. ${ }^{2-5}$

Nos anos 70, o movimento da reforma sanitária se fortalece com a crise da previdência social e diante desse fato, os profissionais de saúde começaram experiências de educação em saúde voltadas para a dinâmica e realidade das classes populares. A participação de profissionais de saúde nas experiências de Educação Popular trouxe para o setor saúde uma cultura de relação com as classes populares que representou uma ruptura com a tradição autoritária e normatizadora da educação em saúde. Com o processo de abertura política, movimentos populares, que já tinham avançado na discussão das questões de saúde, passaram a reivindicar serviços públicos locais e a exigir participação no controle de serviços já estruturados. ${ }^{2}$

A partir de diversas práticas comunitárias e reflexões de cunho teórico e acadêmico, surgiram as bases do que hoje se estabelece a Educação Popular em Saúde (EPS). Diante disso, a EPS começa a compor o cenário político por meio de movimentos populares que se integram como atores políticos ativos no Movimento da Reforma Sanitária. ${ }^{3}$

Nos anos 80 , com a conquista da democracia política e a construção do SUS com a proposta de um novo modelo de atenção em saúde voltado para a prevenção e a integralidade no atendimento, a EPS passou a ser mais difundida. Contudo, os movimentos sociais passaram a lutar por mudanças mais globais nas políticas sociais e os técnicos que estiveram engajados no movimento, passam a ocupar espaços institucionais mais amplos. ${ }^{2-5}$

Com o auxílio do Ministério da Saúde no primeiro ano do governo Lula, realizou-se uma nova configuração entre os movimentos sociais que se articulavam em torno da luta pela saúde. Em uma parceria com a Rede de Educação Popular e Saúde, composta de profissionais da saúde e lideranças criada em 1998, realizaram-se encontros estaduais que culminaram em um encontro nacional no qual se constituiu a Articulação Nacional de Movimentos e Práticas de Educação Popular e Saúde, a qual ficou conhecida por ANEPS. Assim, foi entregue uma carta ao Presidente Lula com a intencionalidade dos movimentos sociais contribuírem com a construção do SUS. Evidenciava-se, então, a EPS como prática necessária à integralidade do cuidado, à qualificação 
da participação e do controle social na saúde e às mudanças necessárias na formação dos profissionais da área. ${ }^{2-3}$

Em 2003 foi instituída a Coordenação Geral de Ações Populares de Educação na Saúde na Secretaria de Gestão do Trabalho e da Educação na Saúde (SGTES). Uma das estratégias implementadas neste momento foi o apoio à constituição de um espaço de interlocução entre os movimentos sociais populares e a gestão do sistema. Em 2005, ocorreram mudanças na gestão federal e com a criação da Coordenação Geral de Apoio à Educação Popular e à Mobilização Social na Secretaria de Gestação Estratégica e Participativa, a EPS é realocada. ${ }^{2-3}$

No ano de 2007, institui-se a Política Nacional de Gestão Estratégica e Participativa (Participa SUS), a qual tem como eixo estruturante a Educação Popular em Saúde. Com isso, fica mais evidente a necessidade de qualificar e dar maior visibilidade a EP. Então, em 2009 institui-se o Comitê Nacional de Educação Popular em Saúde, espaço colegiado com a participação de representantes da gestão do SUS e dos movimentos populares com o objetivo de formular, acompanhar a implementação e avaliar a política de educação permanente. Assim, em 2013 foi implementada a Política Nacional de Educação Popular em Saúde no SUS (PNEP-SUS). ${ }^{3}$

Passados quarenta anos do início deste movimento no Brasil, muita coisa mudou. Muitos espaços foram abertos para a participação popular, inclusive os institucionais como, por exemplo, o "Participa SUS" e a própria Secretária de Gestão Estratégica e Participativa que tem políticas de promoção da equidade construídas e monitoradas por meio dos seus Comitês Técnicos pelos movimentos sociais, com o intuito de construção de políticas de saúde procurando aplicar, neste novo espaço, a metodologia da Educação Popular.

\section{Política Nacional de Educação Popular em Saúde}

Uma das grandes vitórias para a Educação Popular em Saúde foi alcançada quando o Ministério da Saúde, por meio da Secretaria de Gestão Estratégica e Participativa (SGEP), concentrou esforços para a implementação da Política Nacional de Educação Popular em Saúde no SUS (PNEP-SUS). No ano de 2013 com a Portaria no 2.761, de 19 de fevereiro de novembro de 2013, a Educação Popular passa a fazer parte do SUS de forma institucional.

De acordo com sua construção histórica a institucionalização e a construção da PNEPS-SUS é dada por um conceito de horizontalidade, onde a política não é feita "para" o povo, e sim "com" o povo. Sendo assim a PNEPSSUS concebe a Educação Popular como práxis político pedagógica orientadora da construção de processos educativos e de trabalho social emancipatórios para a promoção da autonomia das pessoas, a horizontalidade entre os saberes populares e técnicos- científicos, à formação da consciência crítica, à cidadania participativa, ao respeito às diversas formas de vida, à superação das desigualdades sociais e de todas as formas de discriminação, violência e opressão. ${ }^{3}$

A PNEPS vem sendo adotada como diretriz teórica e metodológica da política de Educação em Saúde do Ministério da Saúde e pode ser considerada uma estratégia prioritária de humanização do SUS e da adequação de suas 
práticas e técnicas na lógica de vida da população, mediante a valorização de formas participativas de relação entre os serviços de saúde e os usuários. ${ }^{6}$

O objetivo geral desta Política é implementar a Educação Popular no âmbito do SUS, contribuindo com a participação, com a gestão participativa, com o controle social, o cuidado, a formação e as práticas educativas. Os seus princípios teóricos -metodológicos são parte articuladas de um processo integral e único, sendo eles: o diálogo que é o encontro de conhecimentos construídos histórica e culturalmente; a amorosidade, permitindo que o afeto torne-se elemento estruturante da busca pela saúde; a problematização, com a leitura crítica da realidade; a Construção compartilhada de conhecimento; a emancipação, processo coletivo e compartilhado onde as pessoas e grupos conquistam a sua superação e libertação de todas as formas de opressão; e o Compromisso com a Construção do projeto Democrático e Popular. E os eixos estratégicos que norteiam o processo de operacionalização são ações que promovam: Participação, Controle Social e Gestão Participativa; Formação, Comunicação e Produção de Conhecimento; Cuidado em Saúde; Intersetorialidade e diálogos Multiculturais. ${ }^{3}$

A PNEP-SUS reafirma o compromisso com a universalidade, a equidade, a integralidade e a efetiva participação popular no SUS. Sua prática políticopedagógica perpassa as ações voltadas para a promoção, proteção e recuperação da saúde, a partir do diálogo entre a diversidade de saberes valorizando os saberes populares, a ancestralidade, o incentivo à produção individual e coletiva de conhecimentos e a inserção destes no SUS. ${ }^{3}$

Com a intenção de reafirmar os princípios do SUS, aponta um diferencial na sua singularidade na contraposição aos saberes e práticas autoritários modelo medicalizantes, biomédico - que estão distantes da realidade social vivida pela sociedade. Longe disso é a exclusão dos saberes técnicos científicos, mas sim a garantia da inclusão dos saberes e práticas populares para as práticas de saúde do SUS. O reconhecimento dos saberes e práticas populares tem o intuito de tornar a legitimar e tirar da invisibilidade, não tendo a intenção de torná-las profissionalizantes ou oficiais.

A intencionalidade desta política pode ser legitimada por diversos marcos legais: A Declaração da Conferência de Atenção Primária em Saúde de AlmaAta (1978), que tem em um de seus objetivos a incorporação de práticas de cuidado; a Carta de Ottawa, que aborda tanto o conceito ampliado de saúde como a capacitação e empoderamento dos indivíduos para o exercício da sua cidadania; a Constituição de 1988, que expressa no artigo no.198 a participação da comunidade e é aprimorada na Lei 8.080/90 e 8,142/90; as últimas Conferências Nacionais de Saúde, que em suas deliberações contemplam estratégias de inclusão das práticas da Educação Popular em Saúde e da sua implementação como política nacional nas três esferas de gestão. ${ }^{3}$

A partir dos espaços que a Educação Popular foi ganhando para dentro do Ministério da Saúde e, consequentemente, do SUS, a mobilização e o protagonismo popular foram ocupando espaços claros para constituir e legitimar o debate político na defesa do direito à saúde. Os ideais da política chegaram no sentido da ação-reflexão-ação mediante a implementação de políticas que contribuem para a melhoria da qualidade de vida e diminuição das desigualdades sociais, as políticas de promoção da equidade. Outro ponto imprescindível se tratando da Educação Popular é a discussão do projeto de sociedade e de saúde mais justo e equânime, no qual a saúde se insere como direito de cidadania e 
dever do Estado. Nesta lógica a política traz competências para os três entes federados.

\section{Contribuições e/ou desafios da Educação Popular em Saúde n Brasil}

Pode-se afirmar que grande parte das experiências de Educação Popular em Saúde está hoje voltada para a superação do fosso cultural existente entre os serviços de saúde, as organizações não-governamentais, o saber médico e mesmo as entidades representativas dos movimentos sociais, de um lado, e, de outro, a dinâmica de adoecimento e de cura do mundo popular. Isto é feito a partir de uma perspectiva de compromisso com os interesses políticos das classes populares, mas reconhecendo, cada vez mais, sua diversidade e heterogeneidade. ${ }^{2}$

É preciso levar a democratização da assistência à microcapilaridade da operacionalização dos serviços de saúde. Sem a participação ativa dos usuários e seus movimentos na discussão de cada conduta ali implementada, os novos serviços expandidos não conseguirão se tornar um espaço de redefinição da vida social e individual em direção a uma saúde integral. ${ }^{2}$

As ações de Educação Popular em Saúde impulsionam movimentos voltados para a promoção da participação social no processo de formulação e gestão das políticas públicas de saúde direcionando-as para o cumprimento efetivo das diretrizes e dos princípios do SUS: universalidade, integralidade, equidade, descentralização, participação e controle social. Ao trabalhar com atores sociais, a Educação Popular contribui para a construção de cenários nos quais os movimentos populares possam se fazer presentes, apresentando novas temáticas, experiências e desejos. ${ }^{7}$

No percurso da Educação Popular na história, ela foi se tornando uma referencial importante para os movimentos sociais e coletivos comprometidos com a transformação social, bem como, para gestões que apresentam a ampliação da democracia e do protagonismo da sociedade civil como princípios básicos de suas políticas. ${ }^{3}$

No seu processo de institucionalização foi se evidenciando a importância e significado do "inédito viável", o novo jeito de fazer da Educação Popular em saúde. Para além foram se validando diversos espaços de encontro de Educação Popular dentro das esferas do SUS com atores implicados com a implementação da PNEPS-SUS. Os espaços das tendas de Educação Popular em saúde Paulo Freire, os Encontros Regionais de Educação Popular, e a criação dos Comitês Técnicos de Educação Popular e Equidade são exemplos de espaços conquistados que passam por processos constantes de ressignificação.

Apesar das práticas de Educação Popular em Saúde já serem desenvolvidas anteriormente a política, o modelo de atenção vigente ainda não permite que estas práticas sejam totalmente legitimadas no âmbito do SUS. Não por ser uma política nova, mas por se configurar de forma contra hegemônica, fazendo uma crítica expressiva à lógica biomédica predominante. Enquanto a Educação Popular busca a reorganização dos serviços de saúde a partir da lógica popular e de um processo libertatório e de superação em pensar o processo saúde-doença, o modelo biomédico busca alimentar o processo de alienação e de dominação. ${ }^{8}$ Percebe-se aí, a importância e a necessidade da incorporação dos princípios e diretrizes da Educação Popular nos currículos dos 
cursos de graduação da área de saúde, já que são esses os profissionais que atuarão no SUS. Esta estratégia contribuiria para que a Educação Popular em Saúde fosse incorporada verdadeiramente na prática desses profissionais, saindo, assim, do campo teórico ou ideológico da saúde.

Para muitos serviços de saúde, a Educação Popular já tem significado um instrumento fundamental na construção histórica de uma medicina integral. $\mathrm{Na}$ dinâmica desses serviços, o diálogo é um conceito fundamental, trazendo o sentido da horizontalidade e colocando os atores da roda em pé de igualdade. Em contraponto, apesar do discurso ser horizontal ainda encontramos uma estrutura verticalizada. ${ }^{8}$

Embora se tenha desenvolvido uma discussão sobre a Educação Popular para dentro do SUS, é real a crise da saúde no Brasil, caracterizada pelo agravamento do quadro crítico do acesso da população aos serviços de saúde. Ou seja, não há garantia de que todos tenham acesso e, para os atendidos, o peso das demandas e as expectativas da população fazem com que 0 atendimento seja medicalizante, quase exclusivamente visando o biológico. ${ }^{10}$

O Debate de repensar a questão da saúde é tão emergencial que foi este o tema da 15a Conferência Nacional de Saúde: Saúde Pública de Qualidade para cuidar bem das pessoas - Direito do povo Brasileiro. E o desafio da Educação Popular continua sendo repensar o inédito viável para garantir o direito à saúde, ação que a Educação Popular já defendeu e sustentou no ideário do Movimento da Reforma Sanitária.

\section{Referências}

1. Gadotti M. Paulo Freire e a Educação Popular. Fase.113. Disponível em: $<$ http://formacaocontinuada.net.br/wp-content/uploads/2015/06/paulofreire-por-moacir-gadotti.pdf >. Acesso em: 4 junho 2016.

2. Vasconcelos EM. Educação Popular: de uma Prática Alternativa a uma Estratégia de Gestão Participativa das Políticas de Saúde. Physis: Rev. Saúde Coletiva. 2004; 14(1):67-83. Disponível em: $<$ http://www.scielo.br/pdf/physis/v14n1/v14n1a05.pdf>. Acesso em: 4 junho 2016.

3. Brasil. Ministério da Saúde. Secretaria de Gestão Estratégica e Participativa. Política Nacional de Educação Popular em Saúde. Brasília: Ministério da Saúde, 2013.

4. Gomes LB.; Merhy EE. Compreendendo a Educação Popular em Saúde: um estudo na literatura brasileira. Cad. Saúde Pública. 2011 jan; 27(1):718.

5. Maciel MED. Educação em saúde: conceitos e propósitos. Cogitare Enferm 2009 Out/Dez; 14(4):773-6.

6. Brandão CR. Educação popular. Brasiliense, São Paulo:1985.

7. Pedrosa JIS. Educação Popular no Ministério da Saúde: identificando espaços e referências. In: Caderno de educação popular e saúde. Ministério da Saúde. Secretaria de Gestão Estratégica e Participativa. Departamento de Apoio à Gestão Participativa, Brasília; 2007. p. 13-17. Disponível em: $<$ http://bvsms.saude.gov.br/bvs/publicacoes/caderno educacao popular saude p1.pdf>. Acesso em: 2 junho 2016. 
8. Vasconcelos EM. Redefinindo as práticas de Saúde a partir de experiências de Educação Popular nos serviços de saúde. Interface Comunicação, Saúde, Educ. 2010 fev, 121-128.

9. BRASIL. Portaria no 2.761, de 19 de novembro de 2013. Institui a Política Nacional de Educação Popular em Saúde no âmbito do Sistema Único de Saúde (PNEPS-SUS). Disponível em: $<$ http://bvsms.saude.gov.br/bvs/saudelegis/gm/2013/prt2761 1911201 3.html>. Acesso em: 2 junho 2016.

10. Valla VV. Educação popular, saúde comunitária e apoio social numa conjuntura de globalização. Cad. Saúde Pública, 1999, 15(Sup. 2):7-14 . 


\section{ANEXOS}

\section{Anexo 1 - Termo de Concordância}

Universidade de Brasília

Faculdade de Ciências da Saúde

Departamento de Saúde Coletiva

Programa de Pós-graduação em Saúde Coletiva

\section{TERMO DE CONCORDÂNCIA}

O Coordenador Geral de Processos da Assessoria de Gestão Estratégicas no Departamento de DST, Aids e Hepatites Virais, Sr. Ivo Brito, está de acordo com a realização, neste Setor, do projeto de intervenção "Política Nacional de Educação Permanente em Saúde: vislumbrando práticas transformadoras na área das DST e aids", de responsabilidade da pesquisadora Ana Luísa Nepomuceno Silva, para qualificação e melhoria das ações educativas desenvolvidas por este Departamento junto aos estados e municípios da federação, após aprovação pelo Comitê de Ética em Pesquisa da com Seres Humanos da Faculdade de Ciências da Saúde da Universidade de Brasília.

O estudo não envolve sujeitos e utilizará base de dados secundária. Tem duração de 6 meses, com previsão de início para janeiro/2016.

Brasília, 02 de janeiro de 2016

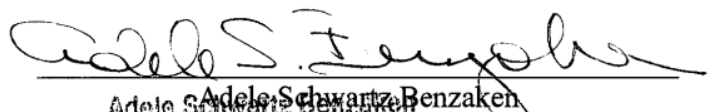

Adevo sAdeban chewarkzenzaken

Diretora do Departamento de DSTraids e Hepatites Virais do Ministério da Saúde

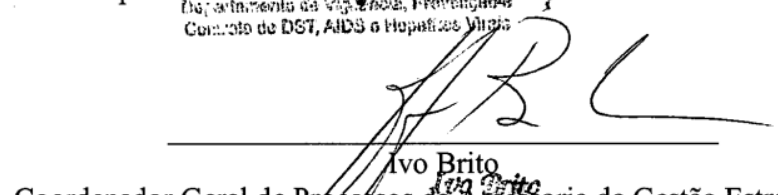

Coordenador Geral deobrefersos d

Dopartamento de DST, Avís é Hepattos Virato

Shepomuano

Ana Luísa Nepomuceno Silva

Pesquisadora 
Anexo 2 - A Rede em imagens
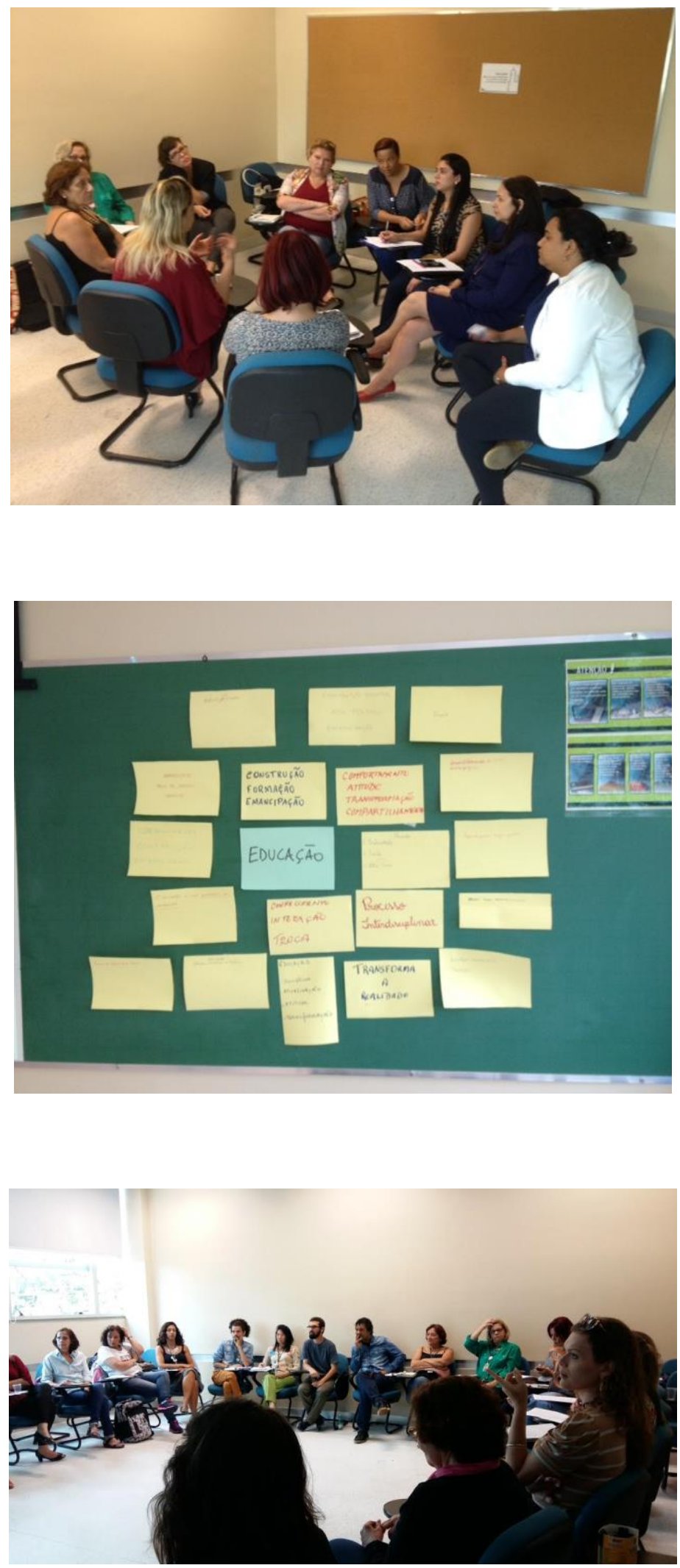

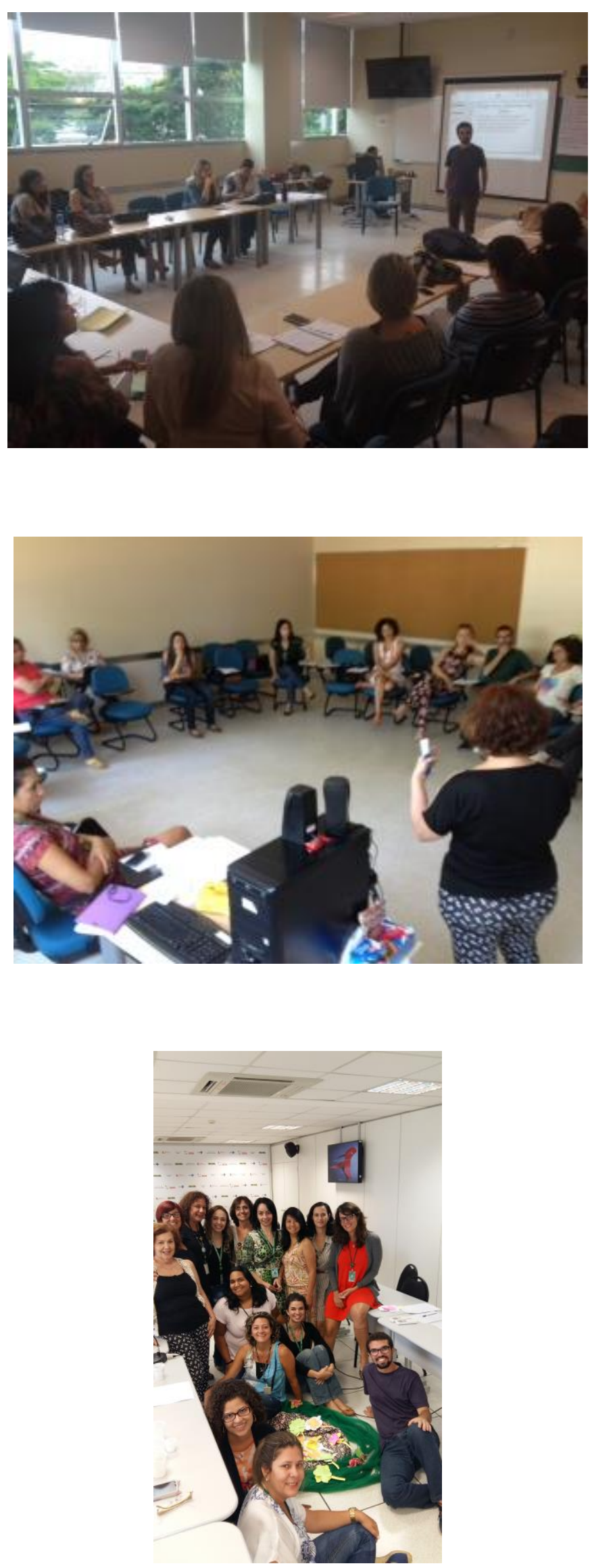